\title{
BIOECONOMY INITIATIVE AT MBI INTERNATIONAL
}

\section{Award No. DE-FG36-07G087005}

$\mathrm{MBI}$ Project No. 1618

\section{FINAL REPORT}

\section{September 1, 2007 - August 31, 2011}

\author{
Submitted to \\ U.S. Department of Energy - Golden Field Office \\ 1617 Cole Boulevard \\ Golden, CO 80401-3305 \\ ATTN: Bryna Berendzen \\ Submitted by \\ 0101 De-Risking and Scale-Up \\ 3815 Technology Boulevard \\ Lansing, MI 48910-8121
}

\begin{abstract}
Project Director :
Dr. Susanne Kleff

Telephone: 517.336.4677

E-mail: kleff@mbi.org
\end{abstract}

\section{Contact:}

E-mail : johnson@mbi.org 


\section{MBI INTERNATIONAL \\ Final Report \\ fOR THe Period September 1, 2007 - August 31, 2011 \\ BIOECONOMY INITIATIVE AT MBI INTERNATIONAL}

\section{$\underline{\text { TABLE OF CONTENTS }}$}

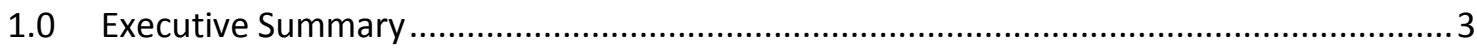

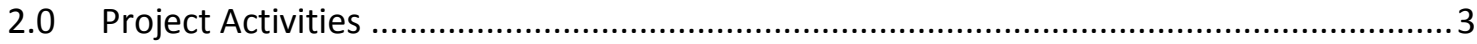

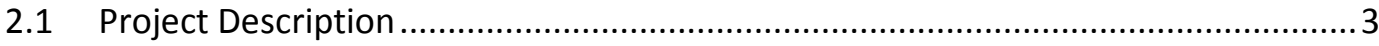

2.2 Task A. Metabolic engineering of organisms

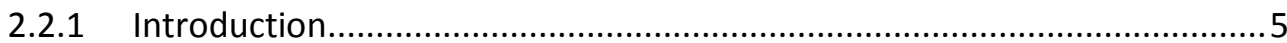

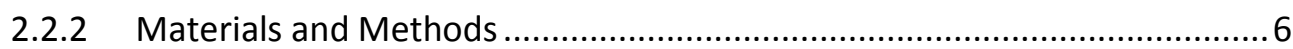

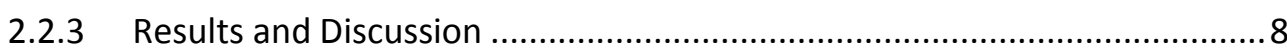

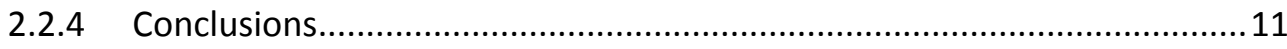

2.3 Task B. Second generation organism for Fumaric acid production

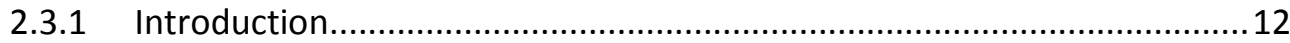

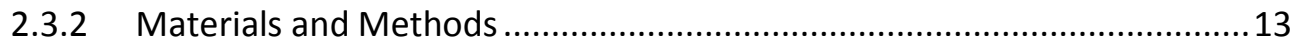

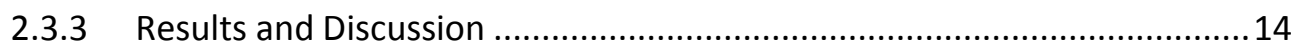

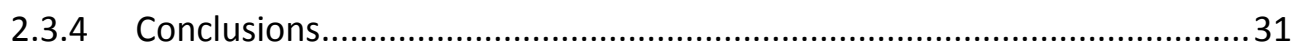

2.4 Task C. Production of fumaric acid from alternative carbon sources

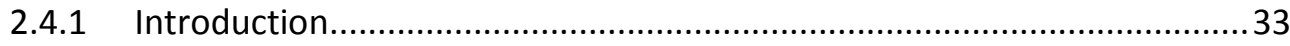

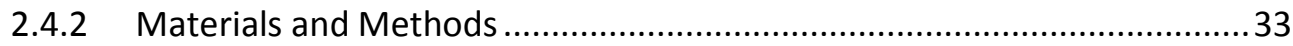

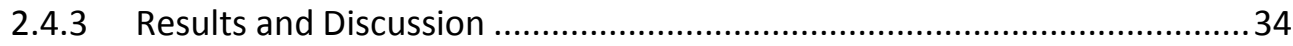

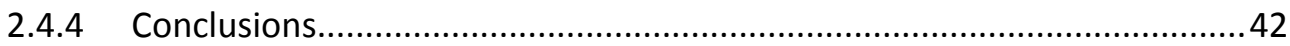

2.5 Task D. Production of other organic acids

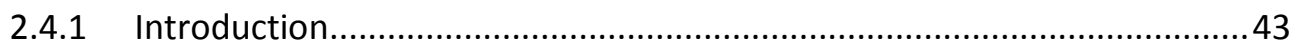

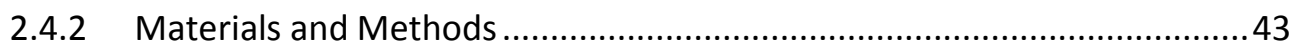

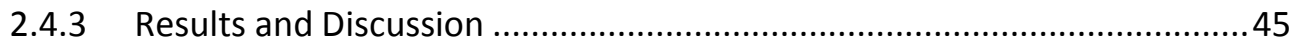

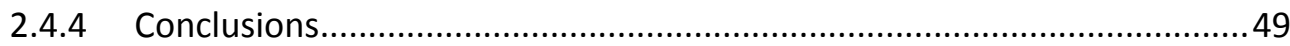

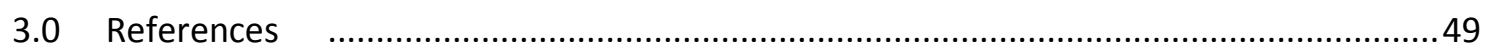

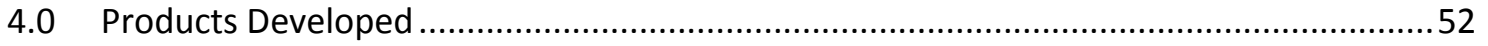




\subsection{Executive Summary}

Di-carboxylic acids have the potential to replace petrochemicals used in the polymer industry (Werpy and Petersen, 2004). MBI developed a process for the production of succinic acid using a proprietary organism. During this work MBI assessed the feasibility to produce other carboxylic acids either using $A$. succinogenes or other organisms.

The development of recombinant $A$. succinogenes strain derivatives for a mono-carboxylic acid through over-expression of enzymatic activities was successful. Fermentations achieved titers of $58 \mathrm{~g} / \mathrm{L}$ for this organic acid. Recombinant strains that produced the same acid, but a different stereoisomer, reached titers of $10 \mathrm{~g} / \mathrm{L}$. Attempts to increase the titers for this isomer as well as other organic acids were unsuccessful. $\mathrm{MBI}$ is looking for commercial partners to pursue the development of recombinant $A$. succinogenes strains for the production of other organic acids.

Attempts to develop recombinant strains of $A$. succinogenes for fumaric acid production through introduction of various antisense RNA constructs were unsuccessful. Alternative suitable organisms were evaluated and Rhizopus oryzae, a natural fumaric acid producer with potential for process improvements, was selected. A novel fermentation and one-step recovery process was developed that allowed capture of IP, produced titers of $>80 \mathrm{~g} / \mathrm{L}$ with a productivity of $1.8 \mathrm{~g} / \mathrm{L}-\mathrm{h}$ and $57 \%$ (g/g glucose) yield. The process was scaled to $2000 \mathrm{~L}$ pilot scale. The economic analysis projected a production cost of $72 \mathrm{c} / \mathrm{lb}$. Recycling and re-use of the base was demonstrated and incorporated into the process. The ability of the organism to produce fumaric acid from other carbon sources and biomass hydrolysate was demonstrated.

The production of other organic acids was evaluated and techno-economic de-risking roadmap documents were prepared.

\subsection{Project Activities}

\subsection{Project Description}

The Department of Energy (DOE) has determined that the di-carboxylic acids in particular have significant potential for displacing petroleum-based chemicals in the manufacture of commodity and specialty chemicals. The availability and the cost of petroleum along with heightened environmental awareness by consumers have increased the interest in chemicals made by fermentation, so called "green chemicals". MBI has developed a proprietary organism, Actinobacillus succinogenes, for the production of succinic acid, a four-carbon, di-carboxylic acid (Guettler et al., 1996). A. succinogenes produces succinic acid with almost theoretical yields via the reverse tri-carboxylic acid (TCA) cycle (Guettler et al., 1999, van der Werf et al. 1997). This route encompasses incorporation of $\mathrm{CO}_{2}$ into phospho-enol pyruvate, PEP, and follows a route that includes several di-carboxylic acids (Yi et al. 2005).

The production of di-carboxylic acids other than succinic by $A$. succinogenes should be possible by blocking or diverting the carbon flow to succinic acid. Molecular biological methods and tools for genetic manipulations of $A$. succinogenes have been developed (Yi et al., 2005). Methods to block the last step in the succinic acid pathway, the conversion of fumarate to succinate by fumarate reductase/succinate dehydrogenase were attempted, using anti-sense RNA expression. This was expected to lead to accumulation of the precursor fumaric acid. This strategy was unsuccessful and alternative production organisms were evaluated. $R$. oryzae (a known fumaric acid producer) was 
selected and process alterations were developed that reproduced the published productivity whilst positively impacting both the fermentation control and the recovery of the acid.

For the production of other organic acids recombinant $A$. succinogenes strains were generated overexpressing enzyme complexes with the goal to channel carbon away from succinic acid towards other organic acids. The approach was successful for a target mono-carboxylic acid, achieving titers of $58 \mathrm{~g} / \mathrm{L}$ via expression of a heterologous enzyme activity, whereas the production of the stereo-isomer (using a heterologous activity) only reached titers of $10 \mathrm{~g} / \mathrm{L}$. The results indicated that protein engineering was needed to achieve further increases in titers. Given the competitive landscape for this acid, the approach was not pursued further. The production of a third dicarboxylic acid through overexpression of a multi-subunit enzyme complex was also not successful. This route was not pursued further, since an alternative route already commercially practiced and well established, and would restrict our ability to capture IP.

Economic analysis of the production processes for organic acids highlighted that the cost of base needed to maintain a near neutral $\mathrm{pH}$ added significant cost. Re-cycling of the base was demonstrated for the fumaric acid process and recovery of $>80 \%$ was achieved. Re-use of the base in subsequent fermentations was demonstrated without impacting fermentation performance.

\section{Objectives:}

- Investigate the feasibility of producing organic acids other than succinic in A. succinogenes.

- Develop a fermentation process using an industrially stable strain for the production of organic acids.

- Assess the feasibility and cost-effectiveness of the current recovery process of organic acids from fermentation broth

- Evaluate alternate recovery and base-recycle processes and assess product purity specifications.

Tasks:

Task A: Metabolic engineering of organisms for the production of fumaric acid

Task A.1 Use of $A$. succinogenes for the production of fumaric acid

Task A.2 Develop a metabolic flux model for R. oryzae.

Task B: Development of a fermentation process

Task B.1 Fermentation process development for fumaric acid

Task B.2 Fed-batch process

Task B.3 Scale up of the fumaric acid production process

Task B.4 Chemical conversions

Task B.5 Economic modeling.

Task C: Fumaric acid production using alternative carbon sources

Task C.1 Alternative carbon sources utilization 
Task C.2 Utilization of biomass derived sugars

Task D: Production of other organic acids

Task D.1 Market analysis

Task D.2 Literature reviews

Task D.3 Reproduce results

\section{Deliverables}

Reports and other deliverables will be provided in accordance with the Federal Assistance Reporting Checklist following the instructions included therein. Specifically, MBI will report on:

1. the production of organic acids by $A$. succinogenes in at least two different media including an economic evaluation,

2. the ability of $A$. succinogenes to produce organic acids other than succinic,

3. the efforts of establishing a method for pathway disruption in A. succinogenes,

4. the production of organic acids in other organisms,

5. the yield and purity of organic acids recovered from fermentation broths under this work, and

6. the economic viability and scalability of literature procedures for conversions of metabolites to market chemicals, and the progress towards developing alternative procedures.

\subsection{Task A: Feasibility of using recombinant organisms for the production of fumaric acid}

\subsubsection{Introduction}

A. succinogenes is a succinic acid producer that displays industrially favorable features, including high product tolerance, high glucose tolerance, and simultaneous use of 6-carbon and 5-carbon sugars. MBI assessed whether the organism's metabolism could be altered to produce other organic acids. Tools and methods for the generation of recombinant strains were established. Attempts were made to redirect carbon away from succinic acid by blocking a pathway step through: i) the use of anti-sense RNA constructs, or ii) the development of a chromosomal integration system to achieve gene knock-outs. $A$. succinogenes nutritional requirements were elucidated in detail, as this organism has complex nutritional requirements that dictate that a yeast extract-containing medium (which is uneconomic) is needed for optimum performance.

Although $A$. succinogenes has favorable characteristics, it was recognized that its performance had to be comparable or exceed the performance of natural fumaric acid producers. $R$. oryzae is a well described (Rhodes et al., 1959; Rhodes et al., 1962), natural fumaric acid producer. The ability of $R$. oryzae to tolerate high product concentrations was ascribed to the insolubility of the Ca-fumarate product in the fermentations (Ling et al. 1989). Under this program it was demonstrated that R.oryzae is equally tolerant of soluble product salts, i.e. Mg-fumarate. Other organic acids are produced co-products. A flux model was developed for $R$. oryzae based on the metabolite profiles and biomass produced, which accounted for $88 \%$ of the carbon input in the fermentation during the acid accumulation phase. 


\subsubsection{Materials and Methods}

Microorganism and Cultivation. Actinobacillus succinogenes FZ45 and other derivatives are stable bacterial variants made by chemical selection of the parent strain Actinobacillus sp. 1302 (ATCC 55618, Guettler et al., 1999; Guettler et al. 1998 US Patent 5,723,322).

A. succinogenes FZ fermentations were performed essentially as described in Guettler, et al. 1999. 50 $\mathrm{mL}$ cultures were carried out in $150 \mathrm{~mL}$ Belco bottles with butyl-rubber stoppers containing $4 \mathrm{~g} \mathrm{MgCO}_{3}$ and $1 \mathrm{~mL} \mathrm{H} \mathrm{H}_{2} \mathrm{O}$. The base was sterilized and the following additions made : $100 \mathrm{~g} / \mathrm{L}$ glucose, $14 \mathrm{~g} / \mathrm{L}$ yeast extract, $8 \mathrm{~g} / \mathrm{L}$ corn steep liquor (CSL), $5 \mathrm{mM} \mathrm{Na-phosphate,} 200 \mathrm{\mu g} / \mathrm{L}$ biotin. Vials were flushed with $\mathrm{CO}_{2}$ and incubated with gentle shaking. Stirred tank fermentations were carried out in the same medium, and used $\mathrm{Mg}(\mathrm{OH})_{2}$ to maintain the $\mathrm{pH}$ at $\mathrm{pH}$ 6.8. All fermentations were carried out at $38 \stackrel{\circ}{ } \mathrm{C}$, with an inoculum volume of $5 \%(\mathrm{v} / \mathrm{v})$.

E. coli was grown in shake flasks in Luria Bertani (LB) medium with/without the appropriate antibiotic at $37^{\circ} \mathrm{C}$, shaking at $200 \mathrm{rpm}$ in a gyrotatory shaker. E.coli strains, $\mathrm{DH} 5 \alpha$, Topo, and Mach1 (Invitrogen) were used for cloning.

R. oryzae growth, fermentation, and biomass determination are described under Task B.

Substrate and product analyses. Succinic acid, glucose, lactic acid, pyruvate, glycerol, ethanol, and formic acid concentrations were determined by HPLC using a Waters 1515 isocratic pump with a Waters 717 auto sampler and a Waters 2414 refractive index detector set at $35^{\circ} \mathrm{C}$. The HPLC system was controlled, and data was collected and processed using Waters Breeze software (version 3.3). A Bio-Rad Aminex HPX-87H $(300 \mathrm{~mm} \times 7.8 \mathrm{~mm})$ column was used with a Cation $\mathrm{H}$ guard column at $55^{\circ} \mathrm{C}$. The mobile phase was $0.021 \mathrm{~N} \mathrm{H}_{2} \mathrm{SO}_{4}$ at $0.5 \mathrm{~mL} / \mathrm{min}$. Samples were filtered through a $0.45 \mu \mathrm{m}$ filter, and 5.0 $\mu \mathrm{L}$ were injected onto the column. Run time was $30 \mathrm{~min}$. A mass flow controller (Brooks model 5850I) was used to monitor and supply $\mathrm{CO}_{2}$ to the fermentor sparging system at $100 \mathrm{~mL} / \mathrm{min}$.

Genetic Manipulations. DNA manipulations followed methods described by Sambrook, 1990. Plasmid DNA was prepared by alkaline lysis. Typical resuspension volumes for multicopy plasmids extracted from $1.5 \mathrm{~mL}$ cultures were $50 \mu \mathrm{L}$. Larger DNA preparations used the Qiagen Plasmid Purification Midi and Maxi kits according to the manufacturer's instructions. Restriction endonucleases, molecular weight standards, and prestained markers were purchased from NE Biolabs and Invitrogen. Digests were performed as recommended by the manufacturer, except that 2-5 fold excess of enzyme was used. DNA was analyzed on agarose gels in the presence of EtBr. DNA was extracted from agarose gels and purified using the Qiagen gel extraction kit according to the manufacturer's instructions. Ligations were performed using a 3-5 fold molar excess of insert to vector DNA in 15-20 $\mu \mathrm{L}$ reaction volumes and $1 \mu \mathrm{L}$ of T4 DNA Ligase (NE Biolabs) according to the manufacturer's instructions. E. coli transformations were carried out using "library efficiency competent cells" purchased from Invitrogen, following the manufacturer's instructions. Transformations using ligation mixes were plated on standard LB plates (Sambrook, 1990), containing the appropriate antibiotic. PCR amplifications were carried out using the Sigma AccuTaq enzyme and reaction set up. Primers were ordered from the Michigan State University Macromolecular Structure Facility or Invitrogen. PCR amplifications were carried out in an Eppendorf Gradient Master Cycler. Starting annealing temperatures were determined using the vector NTI program for each primer pair.

DE-FG36-07G087005

Final Report - 11/29/2011

MBI International

Page $\mathbf{4}$ of $\mathbf{4 9}$ 


\section{Cloning of antisense constructs}

The target transcripts for the antisense constructs were the $A$. succinogenes fumarate reductase/succinate dehydrogenase gene, $\mathrm{Frd}$, and the malate dehydrogenase gene, $\mathrm{Mdh}$. The Frd gene was amplified following standard PCR techniques using primers TD319 and TD320 (5'ACCGTCGACGCTCAATAGTGAACGATGAG-3', and 5'-CACGGCATGCGCGAAGTTTAGTACATCGTC-3'), using genomic DNA from $A$. succinogenes FZ45 as template, cloned into pCR2.1 (Invitrogen) to give generate plasmid pRS889.88.

A vector containing a strong promoter, the $A$. succinogenes phosphoenolpyruvate -carboxykinase (PEPCK), promoter without a translation signal ( $\triangle$ Shine-Dalgarno sequence) was cloned as an EcoRI/Sall fragment amplifying the PEPCK promoter using primers TD325 and TD328 (5'AAAGAATTCTTAATTTCTTTAATCGGGAC, and 5'-TGGTCGACATACTTCACCT) inserted into pJR762.47 (Yi et al., 2005), resulting in pRS889.87.

The antisense constructs were made using pRS889.88 as template for PCR amplifications inserted as Sall/ Sacl fragment into pRS889.87. The resulting plasmid, pEA912.04, had the following insert sequence (short antisense):

TCGACacaacgtcttgttcgcacaaccagtcaccgcccgcaacggtgtcttggaagtgtttgtcataactatcttcttctttgataaccgccgctgcacc gccttcggccgccacggtatggctacgCATcggataaactttaaaagtaattacattagtGAGCTC), with the FrdA DNA in green, CAT is the complementary start codon, capital green, and the 19 base rho-independent terminator of gInA asRNA from Clostridium acetobutylicum in blue, restriction cloning sites in capital black letters.

A long antisense was cloned as a Sall/ Sacl fragment of 1708 bp using the following primers: 5' ttttttgtttttgttttgttttgttttgtcgacttatgcgttaggggctttagc, where Blue DNA is junk DNA to allow for restriction and balanced primers, Aqua DNA is the Sal I restriction site, Green DNA is 5' to 3' antisense DNA from the end of the FrdA coding sequence, and 5'-

Ggctacgcatcggataaactttaaaagtaattacattagtgagctcattcaatt, Red DNA is $5^{\prime}$ to $3^{\prime}$ antisense DNA from the beginning of the FrdA coding sequence, Green DNA is rho-independent terminator of glnA asRNA from Clostridium acetobutylicum, Aqua DNA is Sac I restriction site, Blue DNA is junk DNA to allow for restriction.

An Mdh antisense construct used primers TD342 and TD343 (5'GGgGTCGACTAAATTCTGGATAATACCGG，5'- CACGGATCCGAGGAGTATCTCATGAAAG), Aqua indicating restriction sites. This construct did not contain any termination sequences. The resulting plasmid was pSAW922.81, containing a 312 bp insert covering the immediate beginning of the Mdh RNA.

\section{Cloning of disruption constructs}

The tetracyclin resistance gene (tet gene) was cloned using pBR322 as template and placed under the control of the PEPCK promoter, resulting in $\mathrm{pBH} 827.45$. The promoter and tet gene were amplified from pBH827.45 using primers with $\mathrm{Ncol}$ sites and inserted into the Ncol site of the Adh gene, thereby deleting the central part of the Adh coding region, pREB865.80. A second construct was made using the chloramphenicol resistance gene (chl gene), which was PCR amplified from pNW33N, using primers TD350, TD351, under the control of the PEPCK promoter into pLS88, plasmid pSK912.16, and also inserted into the $\mathrm{Ncol}$ site of $A d h$ containing plasmid giving rise to $\mathrm{pBH} 936.79$ a, deleting approximately $600 \mathrm{bp}$ of the Adh coding region. 
The Lambda RED recombinase was cloned as a Xhol/BamHI fragment into pREB839.80, containing the FZ45 Zwf promoter in our standard expression vector, construct KD725. The construct was transformed into FZ45, and competent cells of the transformant were prepared and stored frozen. This strain was transformed with 500-2000 ng of linear DNA, containing RED recombination ends, $50 \mathrm{bp}$, flanking the disrupted Adh::Pepck-Tet or Adh::Pepck-Chl construct, as linear DNA.

Enzyme assays. Protein concentrations were determined using the Pierce ${ }^{\mathrm{TM}} \mathrm{BCA}$ assay kit. Cell lysates were prepared from growing cultures carrying either the vector or one of the plasmids, described above. Cells were harvested by centrifugation, washed with cold lysis buffer [50 mM potassium phosphate, $\mathrm{pH}$ $7.2,20 \%(\mathrm{v} / \mathrm{v})$ glycerol, $1 \mathrm{mM}$ DTT], and suspended in 1/10 volume of lysis buffer. Cells were disrupted by two passages though a French Press cell at 1300 psig. Cell debris was removed by centrifugation $\left(30,000 \times \mathrm{g}, 20 \mathrm{~min}, 4^{\circ} \mathrm{C}\right)$. Clarified lysates were used for enzyme assays using published procedures. Assays were carried out in triplicate and average data reported

Transformation of $A$. succinogenes. A. succinogenes competent cells were prepared by growing cells in TSB medium. Excess carbonate was removed by centrifugation at $420 \times \mathrm{g}$, for $5 \mathrm{~min}$. Cells were harvested at 6,500 $\times \mathrm{g}$, washed twice with sterile $\mathrm{H}_{2} \mathrm{O}$ and twice with $10 \%(\mathrm{v} / \mathrm{v})$ glycerol and suspended in $0.01 \times$ the original culture volume of $10 \%(\mathrm{v} / \mathrm{v})$ glycerol. Cells were flash frozen and stored at $-80^{\circ} \mathrm{C}$. $40 \mu \mathrm{L}$ aliquots of prepared cells were used for transformation via electroporation; using $0.1 \mathrm{~cm}$ cuvettes and a BioRad GenePulser with settings, $400 \mathrm{~W}, 25 \mathrm{mF}$ and $1.8 \mathrm{kV}$. Following electroporation, $1 \mathrm{~mL}$ room temperature TSB medium was immediately added to the cuvette and incubated at $37{ }^{\circ} \mathrm{C}$ for $1 \mathrm{~h}$. Transformed cells were plated on TSB agar plates containing antibiotic, $100 \mu \mathrm{g} / \mathrm{mL}$ kanamycin, and/or 2$5 \mu \mathrm{g} / \mathrm{mL}$ tetracyclin, and/or $2 \mu \mathrm{g} / \mathrm{mL}$ chloramphenicol.

\subsubsection{Results and Discussion}

Effect of medium on A. succinogenes productivity. A. succinogenes was isolated in an environment containing complex nitrogen sources. The best succinic acid production was achieved with strain FZ45/p830.60, using a medium containing $>10 \mathrm{~g} / \mathrm{L}$ yeast extract. The cost of yeast extract, however, is prohibitive for the industrial production of commodity chemicals. Alternative, mineral medium or media containing inexpensive nitrogen sources were evaluated. The original isolate, $A$. succinogenes $130 z$, had been shown to be able to grow in mineral medium supplemented with 3 amino acid acids, glutamate, cysteine, methionine, (AM3 medium) (McKinley et al, 2005). The FZ strains were derivatives that were selected on fluoroacetate and exhibited decreased or no formate/acetate production. None of the FZ derivatives grew in AM3. Addition of other amino acids and higher amounts of vitamins in the background of a mineral medium achieved only 5-8 g/L succinate in $>100 \mathrm{~h}$. These titers and productivities were not sufficient for an industrial process. The best strain was adapted through serial transfers to a low cost medium in collaboration with a commercial partner, achieving the same titers and productivity as seen with $>10 \mathrm{~g} / \mathrm{L}$ yeast extract.

Development of an anti-sense RNA system capable of interfering with translation of specific mRNAs A plasmid was developed that was able to replicate and be stably maintained in A. succinogenes. A strong, constitutive promoter and translation start signals were incorporated into this plasmid. For the expression of antisense RNA constructs, which are not to be translated, modifications were made to the plasmid that eliminated the translation signals. 
The gene encoding the metabolic step to be interrupted, fumarate reductase, ( $f r d)$, in the annotated $A$. succinogenes $130 \mathrm{z}$ genome sequence was identified and cloned, and two antisense constructs generated. Both antisense constructs incorporated a terminator sequence from the $C$. acetobutylicum GlnA gene to achieve a hairpin structure, which is important for RNA stability and recognition of degradation signals (Desai \& Papoutsakis, 1999). Antisense insertions differed in their length, covering the entire open reading frame of the gene in one construct, or being complementary to only the first 150 nucleotides in the second.

Both constructs were transformed into A. succinogenes. Transformants were grown under standard conditions; metabolites were analyzed and compared with those seen in strains transformed with a vector as control. The vector control and the antisense carrying strain showed identical performance in terms of succinic acid titers, levels of other measured metabolites and biomass produced. Constructs transcribing long or short antisense RNAs were equally ineffective in blocking succinic production.

To confirm that the antisense procedure was effective in $A$. succinogenes, a third antisense plasmid was made targeting the translation of, malate dehydrogenase, mdh, for which a simple, spectrophotometric enzyme assay was available. The construct was complementary to the first 300 nucleotides of the coding RNA. The construct pSAW922.81 was transformed into A. succinogenes, and again caused no decrease in succinic acid production, compared to the vector control. To assess if the antisense RNA had any effect on protein expression, enzyme assays for mdh activity were carried out. A $23 \% \pm 6$ decrease in mdh activity was observed in extracts carrying the antisense constructs. This suggested that the antisense construct was able to interfere with protein translation, but not enough to produce a noticeable phenotype, i.e. reduction of succinic acid production. Three antisense RNA constructs that differed in their lengths and secondary structures were generated during this study in attempts to disrupt succinic acid production in $A$. succinogenes. All attempts using this approach failed. As a result a decision was made to pursue other more tractable approaches for the production of fumaric acid.

\section{Development of a chromosomal integration system for $A$. succinogenes}

Strain improvement of $A$. succinogenes was attempted through the development of a chromosomal integration system. The first integration approach relied on use of an alleged $A$. succinogenes homologous recombination system, as is used in Saccharomyces cerevisae. A presumably, non-essential A. succinogenes gene, alcohol-dehydrogenase, $A d h$, was cloned into a cloning vector. Part of the coding region was replaced with a selective marker, tetracycline resistance from pBR322, expressed from a strong, constitutive $A$. succinogenes promoter. The final construct contains a selectable marker, flanked on either side by $>500 \mathrm{bp}$ of $A$. succinogenes DNA, homologous to chromosomal sequences of $A d h$. The construct was assembled on a plasmid that could not replicate in $A$. succinogenes. Transformations with this plasmid and selection of tetracycline resistant colonies were repeatedly unsuccessful in producing resistant strains.

In another approach, an integration system utilizing a recombinase enzyme (lambda) to enhance the probability of a recombination event was tested. The plasmid expressing the recombinase enzyme was transformed into $A$. succinogenes. Competent cells were made of these transformants, and were transformed in a second round with a linear DNA containing the lambda recombination sites flanking the Adh::tet ${ }^{\text {res }}$ construct described above. No tetracycline resistant colonies were obtained despite multiple attempts. 
As a control, the plasmid expressing the recombinase was tested for a recombination assay in E. coli. Increased recombination frequencies were observed, confirming expression of the recombinase. Failure to obtain chromosomal integration as judged by tet-resistant colonies in A.succinogenes may be due to different recombination or DNA repair proteins in A. succinogenes. Alternatively cells transformed with the recombinase plasmid may be less able to take up the DNA with the integration construct. Transformations were performed in a 2-step process, first transforming with the plasmid encoding the recombinase, then adding the DNA with the disruption construct. Lastly, the concentrations for the tetracycline selection were based on published data (Kim, P. et al., 2004) with the parent $A$. succinogenes strain $130 \mathrm{z}$. It is possible that the FZ derivatives, have a lower tolerance to the antibiotic or require the last succinate production step, fumarate reduction, for energy production. Due to the problems encountered modifying $A$. succinogenes to accumulate fumarate and the progress made on Task $\mathrm{B}$, we focused our efforts on fumaric acid production in $R$. oryzae.

\section{Development of a metabolic flux model for R. oryzae}

As a first step in establishing a metabolic flux model for the filamentous fungus we determined the biomass composition of the organism was determined. Detailed analysis of fermentation broth and biomass composition was carried out during a series of bench scale fumaric acid fermentations. The biomass compositional analysis confirmed that after $\mathrm{N}$-exhaustion (the trigger for fumaric acid accumulation) the composition of the biomass remained constant except for an increase in cellular lipid and is summarized in Figure 1.

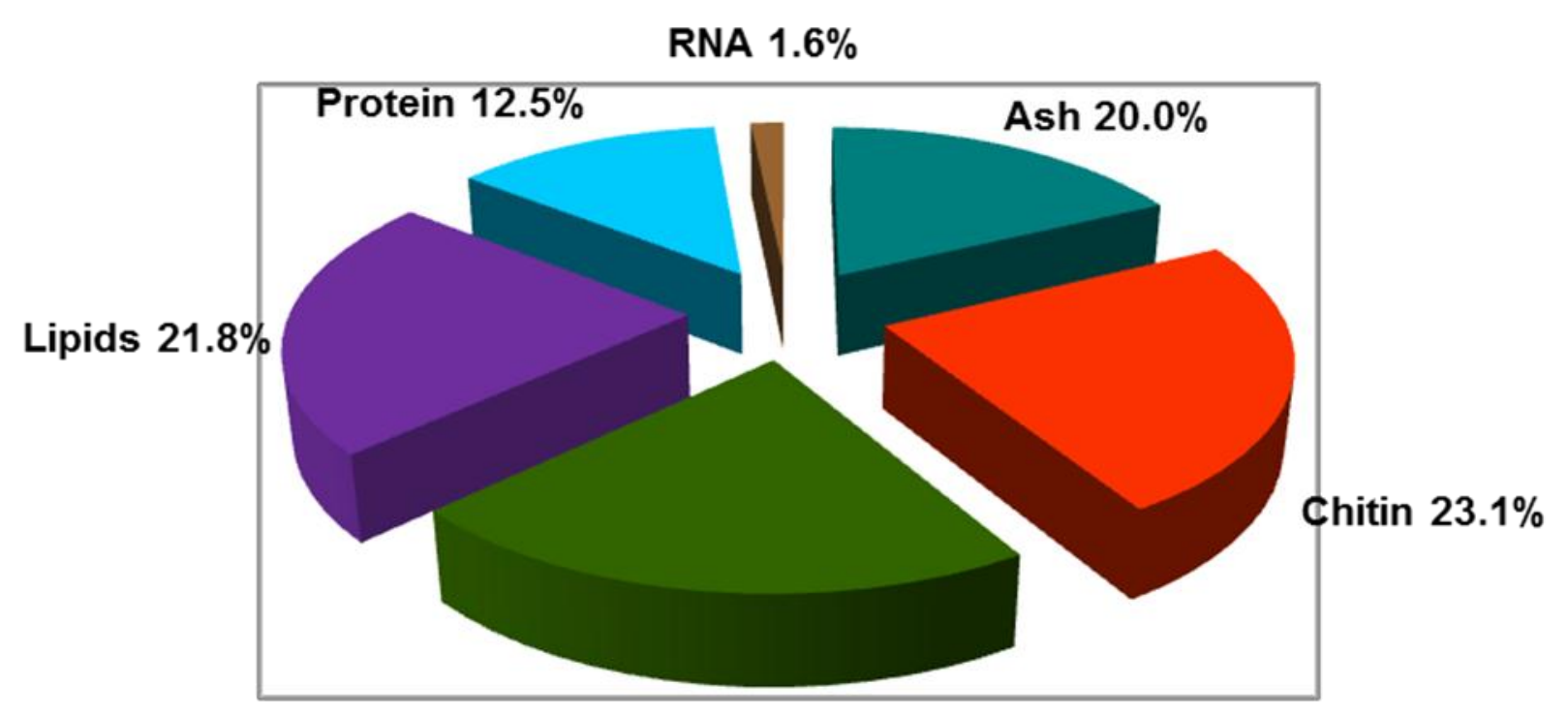

\section{Polysaccharides $\mathbf{2 1 . 0 \%}$}

Figure 1: Compositional analysis of $R$. oryzae. Cell pellets were extracted for proteins, lipids, and the remaining pellet analyzed for chitin by $\mathrm{C} / \mathrm{N}$ analysis, sugars by GC-MS, and ash.

From the rate of glucose consumption and the accumulation of the major fermentation products in the fermentation broth a preliminary metabolic model was constructed. This model accounted for $88 \%$ of the carbon used during the fumaric acid production phase of the fermentation and allowed comparison of potential metabolic engineering strategies to increase fumaric acid yield, the primary driver in the cost of bio-fumaric acid using the mbi process. 


\subsubsection{Conclusions}

Under this task the propensity of $A$. succinogenes as a producer of other organic acids was assessed. Several antisense constructs were made in attempts to decrease the conversion of fumarate to succinate in $A$. succinogenes and engender fumarate accumulation. None of the antisense constructs led to the accumulation of fumaric acid, or a reduction in succinic acid titers or yields in vivo. Control experiments indicated that the antisense RNA decreased the targeted activity in vitro, and may therefore be functional, but antisense RNA was not useful for the development of an industrial process for the production of fumaric acid in this organism.

Chromosomal integration in $A$. succinogenes was attempted. Two approaches were evaluated, one relied entirely on the recombination machinery of the host, a second approach introduced a phage recombinase. Neither of these approaches produced the desired outcome. A laboratory at Michigan State University is pursuing the development, and the technology would become available for licensing to $\mathrm{mbi}$.

A metabolic flux model was developed for the fumaric acid production organism ( $R$. oryzae). This model accounted for $88 \%$ of the carbon used in the fumaric acid producing portion of the fermentation. Although promising targets for co-product minimization and therefore increased fumaric acid yield were identified molecular approaches to improve the production organism were not pursued. Economic analysis of our process indicated that the cost of base needed to maintain the near neutral $\mathrm{pH}$ in the fermentation had a bigger impact on the production cost than elimination of the major by-products. Therefore efforts on the recovery and re-use of base were prioritized. Also the transformation of $R$. oryzae was not straightforward and was made even less attractive as an approach by the publication of a patent application by ADM (Flatland-Bloom et al., 2009) that incorporated the targeted alterations identified as promising by mbi.

\subsection{Task B: Development of a fermentation process for fumaric acid}

\subsubsection{Introduction}

Fumaric acid is a four carbon dicarboxylic acid that was included in the DOE's top ten value added chemicals from biomass (Werpy and Petersen, 2004). Currently the world's production of fumaric acid, some 90,000 tonnes/annum is derived overwhelmingly from petroleum (Roa Engel et al. 2008). The majority of global fumaric acid production, approximately $60 \%$, is used for the production of resins and unsaturated polyesters (UPRs). A more modest, though still significant ( $>30 \%$ of global production), portion of global fumaric acid production is used in food and beverage applications (Roa Engel et al. 2008). The use of fumaric acid in food applications is based upon its acidulent, preservative, flavor enhancing and dough improvement characteristics, which differentiate fumaric acid from other more general purpose acidulents, such as citric acid and phosphoric acid. The food and beverage application is an attractive initial entry point for a bio-based fumaric acid as it commands a higher price point and is an application where the bio-based manufacture can give a natural product a marketable differentiation over a petrochemical-derived product.

Although the current predominant route to fumaric acid is petrochemical, via maleic anhydride (using either benzene or butane as a feedstock), a fermentation process for the production of bio-based fumaric acid has been developed and reported in the literature (Gangl, et al., 1990; Ling and Ng, 1989; Ng et al., 1986; Rhodes, et al., 1959; Rhodes et al., 1962). This process was limited in terms of commercial utility due to undesirable characteristics associated with the requirement for $\mathrm{CaCO}_{3}$ as the 
neutralizing base. The use of $\mathrm{CaCO}_{3}$ resulted in the direct product of the fermentation, conducted at close to neutral $\mathrm{pH}$, being the insoluble calcium fumarate salt. As the insoluble product accumulated during the fermentation, the broth became thixotropic; increasing the viscosity, limiting oxygen mass transfer and increasing the power input required to keep the culture broth well mixed. Formation of an insoluble product that became entrained in the hyphae of the fungal production organism also complicated product recovery. A broth heating step was required to solubilize the calcium fumarate and allow it to be separated from the biomass and other fermentation broth solids. The use of $\mathrm{CaCO}_{3}$ as the base also resulted in the generation of gypsum $\left(\mathrm{CaSO}_{4} \cdot \mathrm{H}_{2} \mathrm{O}\right)$ during the separation/purification of the fumaric acid. The gypsum byproduct constituted an industrial waste and the associated cost of disposal negatively impacted the overall process economics (Gangl, et al., 1990).

Despite its shortcomings the fermentative production of fumaric acid using $\mathrm{CaCO}_{3}$ was practiced in the USA during the 1940s (Roa Engel et al. 2008). However, due in part to the poor characteristics of the fermentation process and partly to the prevailing economics of the time the fermentation route to fumaric acid was displaced by the petrochemical process. More recently with the desire to replace petrochemical derived chemicals and fuels with bio-based, renewable sources (due to economic, environmental and domestic security concerns) the possibility of producing fumaric acid via fermentation is becoming more attractive. This would be especially true if the major detrimental characteristics of the "traditional" fermentation process could be overcome. Against this shifting background an integrated bio-process (fermentation and product separation) has been developed that has distinct advantages over the "traditional" fumaric acid fermentation. This process was developed using an unmodified culture collection strain and has been demonstrated at pilot scale $(2500 \mathrm{~L})$, where it demonstrated performance parameters, both cost of manufacture and product purity, that are appropriate for use in the food and beverage application.

\subsubsection{Material and Methods}

Chemicals. Dextrose monohydrate was obtained from Corn Products U.S., Westchester, IL. All other chemicals were obtained from Sigma-Aldrich, St. Louis, MO.

Organism. The production organism Rhizopus oryzae NRRL 1526 or NRRL2385 were used in all experiments.

Spore generation. The fungus was cultivated on solid medium containing $(\mathrm{g} / \mathrm{L}$ unless otherwise specified); glucose, 4; $\mathrm{CaCO}_{3}$, 3; lactose, 6; glycerol, $10 \mathrm{~mL} / \mathrm{L}$; urea 0.6; corn steep liquor (Fermgold, $50 \%$ w/v solid) $1 \mathrm{~mL} / \mathrm{L} ; \mathrm{KH}_{2} \mathrm{PO}_{4}, 0.4 ; \mathrm{MgSO}_{4} 146 \mathrm{mg} / \mathrm{L} ; \mathrm{ZnSO}_{4} .7 \mathrm{H}_{2} \mathrm{O}, 88 \mathrm{mg} / \mathrm{L} ; \mathrm{FeCl}_{3}, 4.5 \mathrm{mg} / \mathrm{L} ; \mathrm{CuSO}_{4}, 7 \mathrm{mg} / \mathrm{L}$; $\mathrm{MnSO}_{4} .4 \mathrm{H}_{2} \mathrm{O} 38 \mathrm{mg} / \mathrm{L} ; \mathrm{KCl}, 0.4 ; \mathrm{NaCl}, 40$; agar (Bacto), 30 ( $\mathrm{Ng}$ et al., 1986). Plates were incubated for 8 days at $32{ }^{\circ} \mathrm{C}$ and then stored at $4{ }^{\circ} \mathrm{C}$ prior to spore harvesting. Spores were harvested from plates with

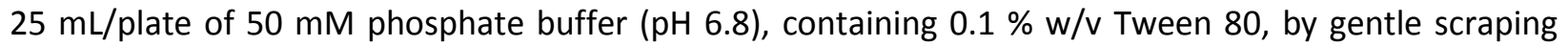
with a sterile inoculating loop. Spores were harvested directly prior to use for inoculation of the germination flasks, spore concentrations in the freshly prepared suspensions were determined using a hemocytometer.

Spore germination. For small scale experiments $500 \mathrm{~mL}$ baffled Erlenmeyer culture flasks containing 180 $\mathrm{mL}$ of germination medium were used; for large scale fermentations $2.8 \mathrm{~L}$ Fernbach flasks containing $900 \mathrm{~mL}$ of medium were used. The germination medium contained ( $\mathrm{g} / \mathrm{L}$ unless otherwise specified) glucose, 40; $\mathrm{MgCO}_{3}$, 2.5; corn steep liquor, $0.5 \mathrm{~mL} / \mathrm{L} ; \mathrm{KH}_{2} \mathrm{PO}_{4}, 1.6 ; \mathrm{MgSO}_{4}, 195 \mathrm{mg} / \mathrm{L} ; \mathrm{ZnSO}_{4} .7 \mathrm{H}_{2} \mathrm{O}, 44$ $\mathrm{mg} / \mathrm{L}$; tartaric acid, $7.5 \mathrm{mg} / \mathrm{L} ; \mathrm{FeCl}_{3}, 4.5 \mathrm{mg} / \mathrm{L} ;\left(\mathrm{NH}_{4}\right)_{2} \mathrm{SO}_{4}, 4$ (6). Germination flasks were inoculated with a final spore concentration of $5-9 \times 10^{6}$ spores $/ \mathrm{mL}$ and incubated at $32{ }^{\circ} \mathrm{C}$ with continuous shaking at 300 
rpm (for $500 \mathrm{~mL}$ Erlenmeyer flasks) on a gyrotory or $190 \mathrm{rpm}$ (for $2800 \mathrm{~mL}$ Fernbach flasks) on a platform shaker. $16 \mathrm{~mL}$ of a $17.24 \% \mathrm{MgCO}_{3} / \mathrm{L}$ slurry were added after $4 \mathrm{~h}$. Total germination culturing was 10-14 h, when the $\mathrm{pH}$ in the spore germination flasks had decreased to 3.0-3.5.

Seed fermentation. Seed fermentors (either $5 \mathrm{~L}$ or $100 \mathrm{~L}$ total volume) were run at $\approx 70 \%$ of nominal capacity as a working volume. The medium used was identical to the spore germination medium (above) with the exceptions that the glucose was increased to $160 \mathrm{~g} / \mathrm{L}$ and the $\mathrm{MgCO}_{3}$ was omitted. The seed fermentor was inoculated, with a $5 \% \mathrm{v} / \mathrm{v}$ seed, from the germination flask(s).

The seed fermentor was maintained at $34^{\circ} \mathrm{C}$ and the set point for $\mathrm{DO}_{2}$ was $80 \%$ (saturation). $\mathrm{DO}_{2}$ was controlled by increasing agitation between $400-800 \mathrm{rpm}$ (in the $5 \mathrm{~L}$ fermentors) or $185-443 \mathrm{rpm}$ (in the $100 \mathrm{~L}$ fermentors). The gas mixture used for aeration was $0.44 \mathrm{vvm}$ air and $0.044 \mathrm{vvm} \mathrm{CO}_{2}$. Culture $\mathrm{pH}$ was maintained at 6.4 by automatic addition of base. Antifoam (Polyglycol P2000) was added as required.

Production fermentation. The production fermentation was carried out using similar culture conditions to the seed fermentation except the $\left(\mathrm{NH}_{4}\right)_{2} \mathrm{SO}_{4}$ concentration in the medium was lowered to $1.8 \mathrm{~g} / \mathrm{L}$. In production tanks $\mathrm{DO}_{2}$ (set point $80 \%$ saturation) was controlled by increasing agitation rates between 400-800 rpm (5 L fermentors) and 60-101 rpm (3700 L fermentor). Initially, $0.44 \mathrm{vvm}$ air was used for aeration, after $12 \mathrm{~h}$ of fermentation a mixture of $0.044 \mathrm{vvm} \mathrm{CO}_{2}$ and $0.44 \mathrm{vvm}$ air was used for the remainder of the fermentation. The production vessels were inoculated with $5 \%(\mathrm{v} / \mathrm{v})$ inoculums from seed fermentors. The seed transfer criterion was based on $\mathrm{N}$-depletion in the seed fermentor (noted as low-point of oxygen utilization rate, OUR, indicated by a sudden increase in $\mathrm{DO}_{2}$ ).

Removal of biomass. At the end of fermentation, determined as the time when glucose was depleted from the fermentation medium, biomass was removed by filtration. At lab scale culture medium, cooled to $4^{\circ} \mathrm{C}$, was filtered through a Komline Sanders 515 filter cloth and the cell free medium retained (at $4^{\circ} \mathrm{C}$ ) for product recovery. At pilot scale the culture was chilled to $12^{\circ} \mathrm{C}$ in the fermentation tank prior to biomass removal and the $\mathrm{pH}$ of the medium adjusted to 4.3. Biomass was removed using a Rotary Drum Vacuum Filter (RDVF, Komline Sanders 2019 filter cloth) and the cell free fermentation beer transferred to a chilled holding tank prior to fumaric acid recovery.

Recovery/purification of fumaric acid. Cell-free fermentation beer was adjusted to $\mathrm{pH}$ 2.3. At lab scale the broth was cooled to $4^{\circ} \mathrm{C}$, at pilot scale the broth was cooled to $11^{\circ} \mathrm{C}$. Once at pH 2.3 the broth was stirred gently for a minimum of $4 \mathrm{~h}$. After incubation the $\mathrm{pH}$ of the broth was determined and readjusted to $\mathrm{pH}$ 2.3. The precipitate formed was recovered by filtration and washed with $\mathrm{dH}_{2} \mathrm{O}$ as part of the collection process using a Rotary Drum Vacuum Filter (RDVF, Komline Sanders 2019 filter cloth).

Biomass determination. 1 or $5 \mathrm{~mL}$ culture samples were collected in pre-weighed centrifuge tubes. Samples were centrifuged at $14000 \times \mathrm{g}$ for $10 \mathrm{~min}$ and the pellets were washed with an initial culture volume of $\mathrm{dH}_{2} \mathrm{O}$ three times. The biomass was lyophilized overnight and the mass determined gravimetrically.

Sugar and organic acid determination. Sugar and organic acid concentrations in the culture filtrates were determined by HLPC. An Aminex HPX-87H (300 mm x $7.8 \mathrm{~mm}$ ) column (Bio-Rad) was used with a mobile phase consisting of $6.5 \mathrm{mM} \mathrm{H}_{2} \mathrm{SO}_{4}$ with a flow rate of $0.4 \mathrm{~mL} / \mathrm{min}$ at a column temperature of $50^{\circ} \mathrm{C}$. Analyte peaks were detected and quantified using a refractive index detector (Waters 2414) and identification of peaks was determined by reference to authentic standards. 
Ammonium determination. Culture ammonium concentration was determined using the indophenol method (Chaney and Marbach, 1962).

Ash determination. Five to $10 \mathrm{~g}$ of sample was accurately weighed into a pre-weighed dry crucible (dried at $550^{\circ} \mathrm{C}$ and stored in a desiccator prior to use). The crucible was placed in a Fischer Scientific Isotherm Muffler Furnace at $550^{\circ} \mathrm{C}$ for a minimum of $3 \mathrm{~h}$. After cooling in a desiccator the final weight of the crucible was determined to establish the weight of ash in the original sample.

Magnesium analysis was performed using a Varian SpectrAA-20 Plus atomic absorption spectrometer. The integrated Automated AA Analysis software was used to develop a five point calibration curve from 0 to $25 \mathrm{ppm}$ and obtain results. Atomic absorption readings were obtained in triplicate and averaged.

General mineral analysis was performed by the Diagnostic Center for Population and Animal Health at Michigan State University. Samples were analyzed for: aluminum, antimony, arsenic, barium, boron, cadmium, calcium, chromium, cobalt, copper, iron, lead, magnesium, manganese, mercury, molybdenum, phosphorus, potassium, selenium, sodium, sulfur, thallium, and zinc by ICP-AES.

Chemical purity of organic acids: One gram of the acid was accurately weighed into a $25 \mathrm{~mL}$ volumetric flask. The sample was dissolved in deionized water with $4 \mathrm{~N} \mathrm{NaOH}$ added as needed to convert the acid to the more soluble salt form. The solution was filtered and analyzed by HPLC. The purity was determined by dividing concentration, measured by the HPLC, by the calculated concentration, based on the weight and dilution.

Broth clarification for fumaric acid: Fermentation broth containing fumaric acid was clarified by vacuum filtration through Fisher brand P5 filter paper (cat. No.: 09-801A) covered with a $1 \mathrm{~cm}$ layer of celite 545. Alternatively broth was filtered through a Fisher brand P5 filter paper and the broth was recycled through the filter and filter cake until the filtrate appeared clear.

Direct acidification procedure: Concentrated $\mathrm{H}_{2} \mathrm{SO}_{4}$ was added to clarified fermentation broth. The mixture was cooled to $4^{\circ} \mathrm{C}$ and crude crystals were collected by vacuum filtration. Crude crystals were dissolved in $\mathrm{DI} \mathrm{H}_{2} \mathrm{O}$ and filtered through a carbon column. The decolorized solution was concentrated and crystals collected as previously described.

Recovery of fumaric acid: Fermentation broth containing magnesium fumarate was filtered through a 1 $\mathrm{cm}$ think layer of 545 celite to remove any suspended solids. The filtrate was acidified (using $\mathrm{H}_{2} \mathrm{SO}_{4}$ ) to $\mathrm{pH} 1.8$ and cooled to $4^{\circ} \mathrm{C}$. The fumaric acid precipitate was collected by vacuum filtration and dried in a vacuum oven $\left(47^{\circ} \mathrm{C} @ 15\right.$ in $\left.\mathrm{Hg}\right)$.

Esterification of fumaric acid: A $5 \mathrm{~L}$ three neck round bottom flask was fitted with a fractional distilling and mechanical stirrer. The flask was charged with $1240 \mathrm{~g}$ of commercial $99 \%$ fumaric acid dissolved in $2.7 \mathrm{~L}$ of absolute ethanol. $5 \mathrm{~mL}$ of concentrated $\mathrm{H}_{2} \mathrm{SO}_{4}$ were added. The reaction was heated to and maintained at reflux for $18 \mathrm{~h}$. One liter of solvent was then distilled and replaced with fresh absolute ethanol. This was repeated (four times) until a GC analysis of the reaction solution showed the reaction to be greater than $97 \%$ complete. . The solution was neutralized by addition of $200 \mathrm{~mL}$ of IRA 96 weak base anion exchange resin and stirred for $18 \mathrm{~h}$. The resin was removed by filtration, and washed with $500 \mathrm{~mL}$ ethanol. The ethanol wash and the filtrate were combined and the ethanol was removed by vacuum distillation (28 in $\mathrm{Hg}$ ). 
$\mathrm{MgSO}_{4}$ recovery: After recovery of the fumaric acid (see above) the $\mathrm{MgSO}_{4}$ containing aqeous stream was concentrated under vacuum to $\approx 40 \%$ of its original weight. Absolute ethanol 2:1 (volume to weight) was added and precipitated $\mathrm{MgSO}_{4}$, was collected by filtration, and washed twice in fresh ethanol.

Conversion of $\mathrm{MgSO}_{4}$ to $\mathrm{Mg}(\mathrm{OH})_{2}$ : $\mathrm{MgSO}_{4}{ }^{*} 6 \mathrm{H}_{2} \mathrm{O}$ was dissolved in $\mathrm{DI}$ water $(15 \% \mathrm{w} / \mathrm{w})$ and concentrated $\mathrm{NH}_{4} \mathrm{OH}$ (15 eq.) added slowly. The reaction temperature and rate of addition was varied as detailed in the results and discussion section. Precipitated $\mathrm{Mg}(\mathrm{OH})_{2}$ was collected by vacuum filtration and washed.

\subsubsection{Results}

Comparison of Different Base Composition. In an attempt to overcome the issues associated with the use of $\mathrm{CaCO}_{3}$ as the base in the fumaric acid process and the generation of an insoluble product ( $\mathrm{Ca}$ fumarate), a range of alternative bases were tested that produce a soluble salt of fumaric acid. The bases tested were $\mathrm{NaOH}, \mathrm{KOH}$ and $\mathrm{Mg}(\mathrm{OH})_{2}$. All fermentations were carried out under identical conditions with the exception of the base used. Neither $\mathrm{NaOH}$ nor $\mathrm{KOH}$, when used as the base, supported the production of large amounts of extra-cellular fumaric acid by $R$. oryzae (Fig. 2). When these two bases were used, the fumaric acid concentration in the fermentation broth did not exceed 35 $\mathrm{g} / \mathrm{L}$ and similar amounts of malic acid and glycerol were produced. The glucose utilization in these fermentors was incomplete, even after an extended fermentation time of $96 \mathrm{~h}$. In contrast when $\mathrm{Mg}(\mathrm{OH})_{2}$ was used as the base the fermentation depleted glucose at $65 \mathrm{~h}$ and the final fumaric acid concentration exceeded $70 \mathrm{~g} / \mathrm{l}$, whilst malic acid accumulated to $22 \mathrm{~g} / \mathrm{L}$.

A) $\mathrm{NaOH}$

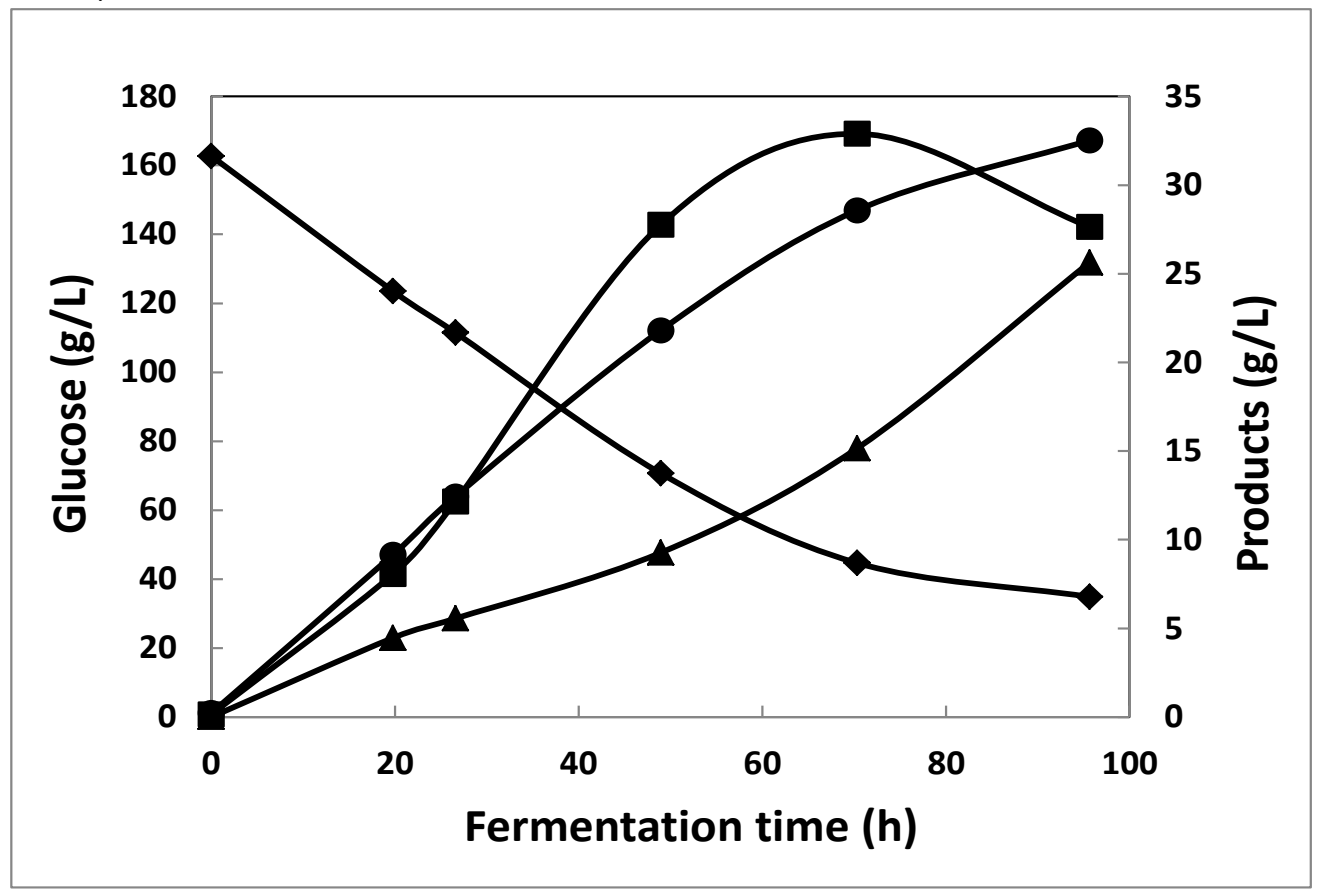


B) $\mathrm{KOH}$

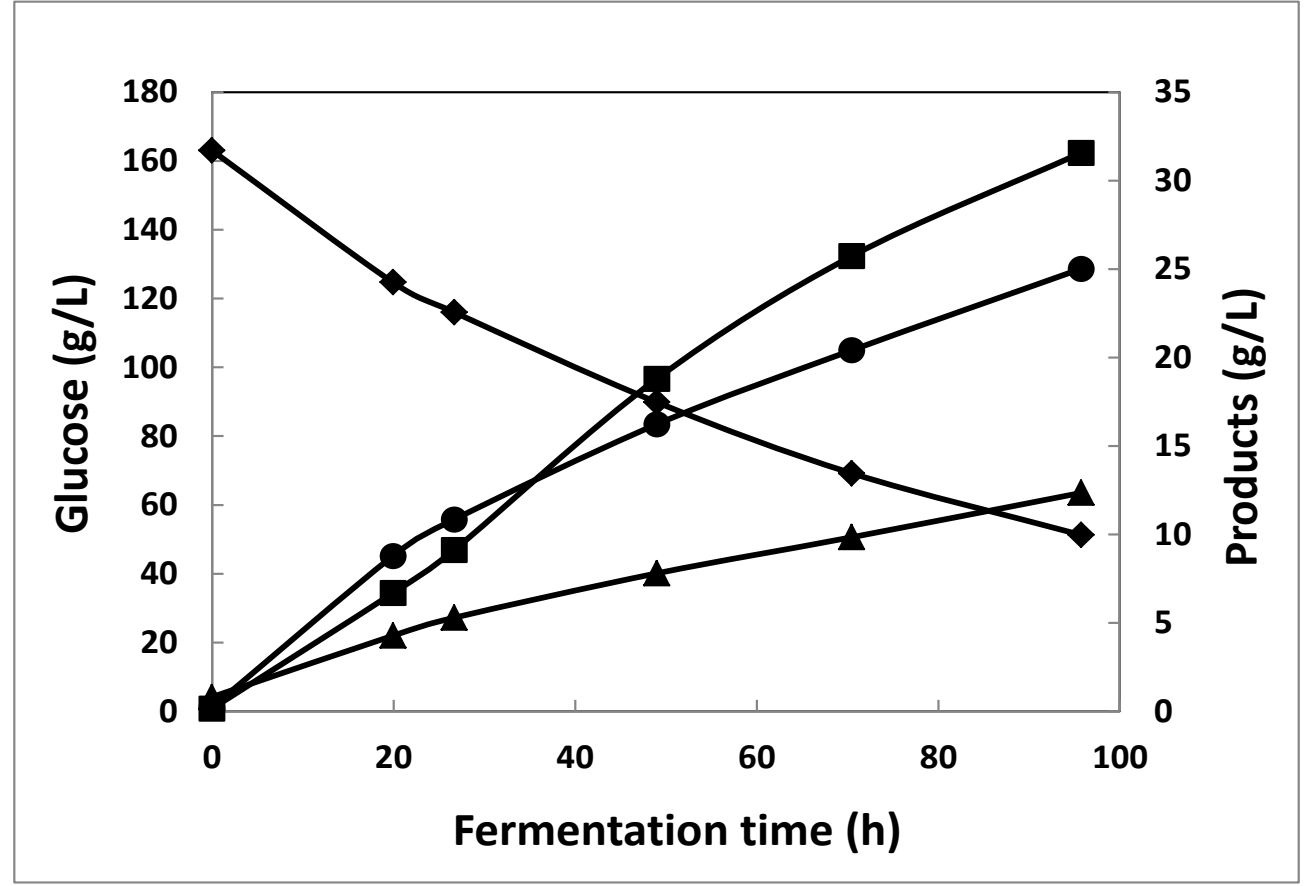

C) $\mathrm{Mg}(\mathrm{OH})_{2}$

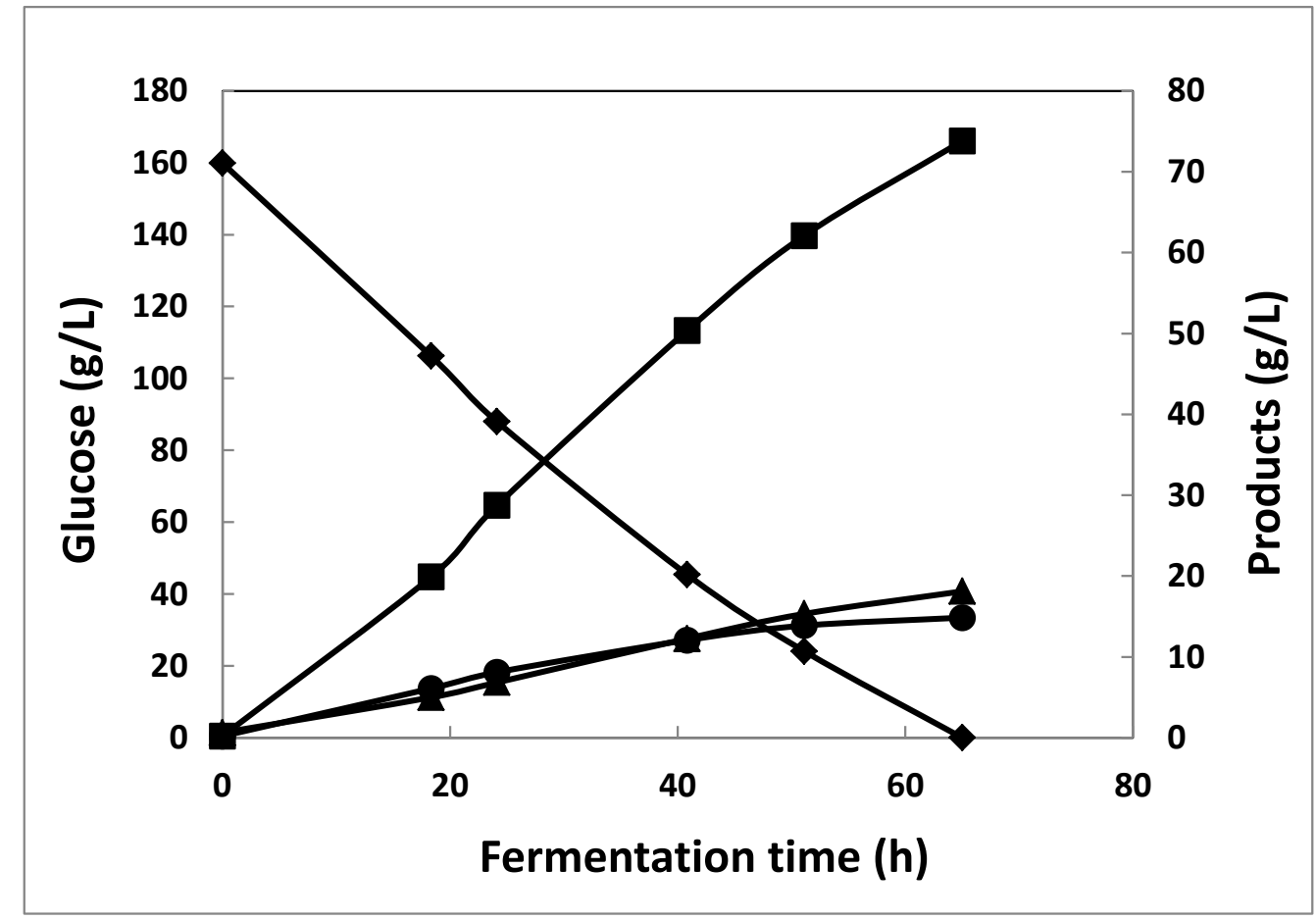

FIG. 2. Production of fumaric and other organic acids from glucose with different bases. $\downarrow$ glucose

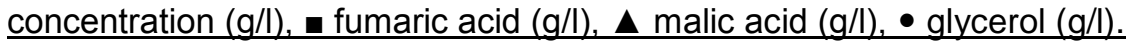


Effect of Culture pH. Having determined that $\mathrm{Mg}(\mathrm{OH})_{2}$ was a suitable base for $\mathrm{pH}$ control in the fumaric acid fermentation the influence of other cultivation parameters on the fermentation process was assessed. A pH range between 6.0 and 7.2 was tested, $\mathrm{pH}$ was maintained using $5 \mathrm{M} \mathrm{Mg}(\mathrm{OH})_{2}$. Although all $\mathrm{pH}$ set points supported significant fumaric acid accumulation $(>40 \mathrm{~g} / \mathrm{L})$, there were significant differences between the process performances over the tested $\mathrm{pH}$ range. Fermentation productivity and final fumaric acid yield increased between pH 6.2 and 6.8, however both decreased at pH 7.2 (Figure 3). The best fermentation performance was obtained at $\mathrm{pH} 6.8$ and this $\mathrm{pH}$ set point was selected as the basis for further process development.

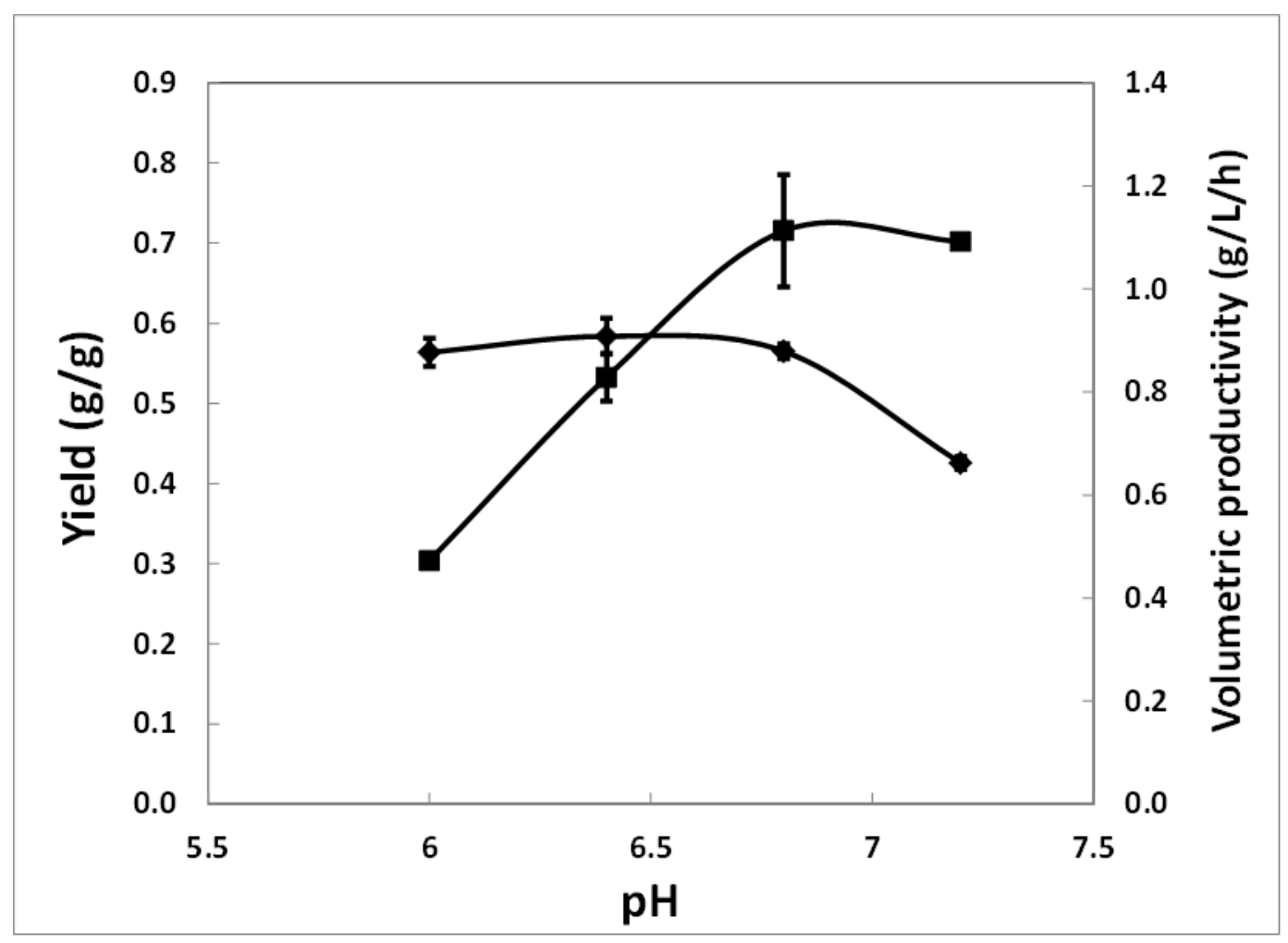

FIG. 3. The impact of culture $\mathrm{pH}$ on the productivity ( $\mathrm{g}$ fumaric acid/l.h) and vield (g fumaric acid/g glucose) was assessed between $\mathrm{pH} 6.0$ and 7.2. $\mathrm{productivity,} \mathrm{yield}$

$\mathrm{CO}_{2}$ supplementation of sparge gas. The proposed metabolic path for the synthesis of fumaric acid in $R$. oryzae utilizes the reductive TCA cycle route (Kenealy, et al., 1986). Therefore the carboxylation of pyruvate (to form oxaloacetate) by a cytosolic pyruvate carboxylase is hypothesized to be a key step in the pathway (Osmani and Scrutton, 1985; Overman and Romano, 1969). As a consequence of this carbon fixing step in the biosynthetic pathway it was considered possible that supplementation of $\mathrm{CO}_{2}$ to the sparge gas would benefit the fermentation. Supplementation with $5-15 \% \mathrm{CO}_{2}$ was tested (data not shown), and appeared to benefit the fermentation at all levels of addition, although the improvement was small. For future development the supplementation of sparge gas with $10 \% \mathrm{CO}_{2}$ was employed in the base process. The developed process exhibited a productivity of $>1.3 \mathrm{~g}$ fumaric acid/L.h and a yield of $>0.55 \mathrm{~g}$ fumaric acid/g glucose. 
Effect of nitrogen concentration and the phosphorus/nitrogen ratio. The amount of biomass produced is limited by the amount of nitrogen in the fermentation medium. Higher amounts of nitrogen should lead to more biomass formation, and increased productivity. Conversely, higher biomass would reduce the yield of fumaric acid from glucose. A series of experiments were carried out to assess the effects of $\mathrm{N}$ and $\mathrm{P}$ concentrations on fermentation performance.

Fermentations were carried out, in which the concentration of $\left(\mathrm{NH}_{4}\right)_{2} \mathrm{SO}_{4}$ was increased by $10 \%(1.98$ $\mathrm{g} / \mathrm{L})$ and $20 \%(2.16 \mathrm{~g} / \mathrm{L})$ at the start of fermentation (Table 1). A 10\% nutrient increase improved the productivity, while the yield remained unchanged. Higher biomass produced caused a decrease in the yield. A $20 \%$ nutrient increase significantly decreased the selectivity towards fumaric acid; higher amounts of malic acids were made, thereby decreasing the specific fumarate productivity and yield. In view of this data a lower starting $\left(\mathrm{NH}_{4}\right)_{2} \mathrm{SO}_{4}$ concentration $(1.1 \mathrm{~g} / \mathrm{L})$ was tested. Lowering the nitrogen concentration by $40 \%$ also lead to the accumulation of more malate co-product, thereby decreasing fumaric acid yield.

Altering the amount of $\left(\mathrm{NH}_{4}\right)_{2} \mathrm{SO}_{4}$ in the medium changed the phosphorus/nitrogen ratio. In a second set of experiments the concentration of $\left(\mathrm{NH}_{4}\right)_{2} \mathrm{SO}_{4}$ was decreased whilst maintaining N/P ratio (1.05). Maintaining the N/P ratio when the total $\mathrm{N}$ in the medium was decreased mitigated the increase in the production of malate observed previously. It appeared that the N/P ratio was critical and needed to be maintained in a narrow range to control the fumarate/malate ratio in the resultant fermentation broth (Table 1).

The effect of increased concentrations of $\left(\mathrm{NH}_{4}\right)_{2} \mathrm{SO}_{4}$ in Stage 3 seed fermentors was tested and yielded similar results. It was expected that higher nitrogen in the seed would lead to higher amount of biomass. A higher density inoculum would provide a higher starting cell density in the production fermentors, decreasing the length of growth phase and improving productivity. Higher nitrogen concentrations did result in higher biomass in the inoculum. However, it decreased the fumarate accumulation (and more malate production) and thereby decreased the fumarate productivity. A fermentation inoculated with a seed having $8 \mathrm{~g} / \mathrm{L}\left(\mathrm{NH}_{4}\right)_{2} \mathrm{SO}_{4}$, exhibited a lower fumarate/malate ratio than fermentors inoculated with a seed containing $4 \mathrm{~g} / \mathrm{L}\left(\mathrm{NH}_{4}\right)_{2} \mathrm{SO}_{4}$ 
Table 1: Effect of nitrogen concentration and phosphorus/nitrogen ratio variations on fumaric acid fermentations.

\begin{tabular}{|c|c|c|c|c|c|c|}
\hline $\begin{array}{c}\left(\mathrm{NH}_{4}\right)_{2} \mathrm{SO}_{4} \text { in seed } \\
{[\mathrm{g} / \mathrm{L}]}\end{array}$ & $\begin{array}{c}\left(\mathrm{NH}_{4}\right)_{2} \mathrm{SO}_{4} \text { in } \\
\text { prodctn [g/L] }\end{array}$ & $\begin{array}{c}\mathrm{N} / \mathrm{P} \\
\text { Ratio }\end{array}$ & $\begin{array}{c}\mathrm{FA} \\
\text { Titer } \\
{[\mathrm{g} / \mathrm{L}]}\end{array}$ & $\begin{array}{c}\text { Yield } \\
\text { [g-fa/ } \\
\text { g-glu] }\end{array}$ & $\begin{array}{c}\text { Productivity } \\
\text { [g/L-h] }\end{array}$ & $\begin{array}{c}\text { Eq Base per } \\
\text { eq FA }\end{array}$ \\
\hline 6 & $\mathbf{1 . 8}$ & 1.05 & 75 & 0.58 & 1.45 & 1.34 \\
\hline 6 & $\mathbf{1 . 9 8}$ & 1.15 & 74 & 0.57 & 1.47 & 1.36 \\
\hline 6 & $\mathbf{2 . 1 6}$ & 1.25 & 68 & 0.51 & 1.39 & 1.54 \\
\hline 4 & 1.1 & $\mathbf{1 . 0 5}$ & 70 & 0.6 & 0.99 & 1.36 \\
\hline 4 & 1.1 & $\mathbf{0 . 6 5}$ & 61 & 0.56 & 0.86 & 1.23 \\
\hline $\mathbf{4}$ & 1.8 & $\mathbf{0 . 9 5}$ & 76 & 0.58 & 1.44 & 1.45 \\
\hline $\mathbf{8}$ & 1.98 & 0.87 & 75 & 0.55 & 1.45 & 1.44 \\
\hline
\end{tabular}

Effect of higher DO set point with higher nitrogen concentration. An increase in $\mathrm{N}$ concentration in the medium led to an increase in biomass and increased the productivity. A fermentation set up with a $20 \%$ higher nitrogen had shown poor performance, suggesting that the mass transfer of oxygen might not have been sufficient during growth phase. The DO set point was increased from $80 \%$ to $100 \%$ and DO was controlled using agitation in the range of $400-800 \mathrm{rpm}$. The higher DO set point ramped up agitation faster, improving aeration for cell growth and improving the fungal morphology (generating small pellets, due to an increase in shear). These changes resulted in higher productivity and decreased malate accumulation. These results supported the necessity of aerobic conditioning (probably due to improved morphology) of the biomass during growth phase to increase the subsequent fumaric acid production.

Table 2: Effect of higher DO set point (100\%) on fermentation performance.

\begin{tabular}{|c|c|c|c|c|c|}
\hline DO set point (\%) & $\left(\mathrm{NH}_{4}\right)_{2} \mathrm{SO}_{4}(\mathrm{~g} / \mathrm{L})$ & $\begin{array}{c}\text { FA Titer } \\
(\mathrm{g} / \mathrm{L})\end{array}$ & $\begin{array}{c}\text { Yield } \\
\text { (g- } \\
\text { fa/g- } \\
\mathrm{glu})\end{array}$ & $\begin{array}{c}\text { Productivity } \\
(\mathrm{g} / \mathrm{L} / \mathrm{h})\end{array}$ & $\begin{array}{c}\text { Eq base } \\
\text { per eq FA }\end{array}$ \\
\hline 80 & $\begin{array}{c}2.16 \\
(\uparrow 20 \%)\end{array}$ & 72 & 0.55 & 1.38 & 1.35 \\
\hline 100 & $\begin{array}{c}2.16 \\
(\uparrow 20 \%)\end{array}$ & 74 & 0.56 & 1.48 & 1.41 \\
\hline 100 & $\begin{array}{c}2.16 \\
(\uparrow 20 \%)\end{array}$ & 76.1 & 0.57 & 1.62 & 1.33 \\
\hline
\end{tabular}


Effect of higher aeration and agitation with higher nitrogen concentration. A higher DO set point led to a faster ramp up of agitation and improved the performance of the fermentation. An increased sparge rate, from 0.44 to $0.88 \mathrm{vvm}$, was tested to establish if this could accomplish the same result. Increasing aeration alone lead to decreased titer and lower productivity (Table 3 ). It was likely that higher air flow was only beneficial if the mass transfer was also improved by providing better mixing. The agitation range for controlling DO set point was increased to $800-900 \mathrm{rpm}$. Increased agitation combined with aeration resulted in a higher mass transfer and faster growth. Improved productivity $(1.73 \mathrm{~g} / \mathrm{L} / \mathrm{h})$ and titer were obtained with no loss in yield when increased agitation, aeration and culture nitrogen content were combined (Table 3). Due to the beneficial impact of increased aeration and agitation alongside increased initial nitrogen content of the medium a revised "base case" fermentation process was established; using $2.16 \mathrm{~g} / \mathrm{L}\left(\mathrm{NH}_{4}\right)_{2} \mathrm{SO}_{4}, 0.88 \mathrm{vvm}$ aeration and 800-900 rpm agitation.

Parallel to the effect of agitation, the impact of higher nutrient levels at a higher DO set point was also tested. A $30 \%$ increase in the amount of nitrogen (while maintaining the phosphorus/nitrogen ratio) produced slightly more biomass and thereby improved productivity (to $1.8 \mathrm{~g} / \mathrm{L} / \mathrm{h}$ ), maintained high selectivity to fumarate $(74 \%)$, and gave only a small decrease in yield (Table 3 )

Table 3: Effect of aeration, agitation and nitrogen concentration level on fermentation performance. DO set pt was $100 \%$.

\begin{tabular}{|l|c|c|c|c|c|}
\hline $\begin{array}{l}\text { Agitation range for } \\
\text { DO control (rpm) }\end{array}$ & $\begin{array}{c}\text { Air flow } \\
(\mathrm{vvm})\end{array}$ & $\begin{array}{c}\left(\mathrm{NH}_{4}\right)_{2} \mathrm{SO}_{4} \\
(\mathrm{~g} / \mathrm{L})\end{array}$ & $\begin{array}{c}\mathrm{FA} \\
\text { Titer } \\
(\mathrm{g} / \mathrm{L})\end{array}$ & $\begin{array}{c}\text { Yield } \\
(\mathrm{g} \text {-fa/g-glu })\end{array}$ & $\begin{array}{c}\text { Productivity } \\
(\mathrm{g} / \mathrm{Lh})\end{array}$ \\
\hline $400-800$ & 0.44 & $20 \% \uparrow$ & 76.1 & 0.57 & 1.62 \\
\hline $400-800$ & 0.88 & $20 \% \uparrow$ & 78.3 & 0.57 & 1.56 \\
\hline $800-900$ & 0.88 & $20 \% \uparrow$ & 79.7 & 0.57 & 1.73 \\
\hline $400-900$ & 0.88 & $30 \% \uparrow$ & 79.0 & 0.56 & 1.80 \\
\hline
\end{tabular}

Effect of inoculum volumes. Fumaric acid fermentations involve an initial growth phase, followed by an acid production phase. Exhaustion of nitrogen in the medium limits the growth of the organism and redirects the carbon flux into acid production. Shortening the time of growth phase of the organism would trigger an earlier start of the acid production and improve productivity. Shortened growth phase is possible using a higher inoculum volume. This provided a higher initial biomass, which consumed the nitrogen faster, thereby stimulating acid production earlier in the fermentation. Previous studies showed that the productivity was significantly decreased when lower inoculum volumes (1\%, and $2 \%)$ were used compared to the standard inoculum volume (5\%). To be consistent with the concept of higher overall productivity using higher starting biomass, a fermentation was carried out, wherein a higher starting inoculum (7.5\%) was used for the production fermentor. The growth phase was shortened by an hour, and fumaric production started earlier compared to the control fermentation. The fermentation maintained the fumarate titer, yield, and selectivity, but there was only a small increase in volumetric productivity compared to the control fermentation (data not shown). The increase in productivity was within the experimental variation, which suggested that higher inoculums did not provide significant advantage to boost the productivity. 
In the current fumaric acid fermentation it was demonstrated that the maintenance of the N/P ratio was critical and had to be maintained at 1.05 to achieve the required production of fumaric acid. $\mathrm{N}$ and $\mathrm{P}$ concentrations were increased by $20 \%$ to achieve higher productivity (of $25 \%$ ) while ensuring that there was a minimal loss in yield $(\approx 2 \%)$. Increased agitation during the growth phase was beneficial due to improved oxygen mass transfer. Increased shear also helped generate small fungal pellets that contributed to a decrease in culture viscosity and helped maintain a higher DO concentration in fermentation broth which improved fumarate productivity. Higher inoculum volumes did not improve fermentation performance.

Glucose Fed-batch fermentations. Glucose cost was identified as an important cost driver in fumarate production, therefore improving yield was a priority. Fed-batch fermentations are a well-established approach to increasing product yield, increasing the product titer and maximizing biomass use.

Fed-batch: effect of feed starting time. Two fed-batch regimens were tested for the production of fumaric acid. For a continuous feed, glucose syrup was fed from $36-72 \mathrm{~h}$. Under these conditions the fermentation continued to produce fumaric acid until all the glucose was consumed and the titer reached $>98 \mathrm{~g} / \mathrm{L}$. For a bolus-feed strategy, glucose syrup was added four times after $42 \mathrm{~h}$. With the bolus feed the fermentation produced fumaric acid at $>1 \mathrm{~g} / \mathrm{L}-\mathrm{h}$ through $90 \mathrm{~h}$ when all the glucose was consumed and the concentration of fumaric was $>107 \mathrm{~g} / \mathrm{L}$. These experiments demonstrated that the glucose feeds can be used to achieve product concentrations $>10 \%$.

The initiation time for the glucose feed was investigated further. Four time-points were chosen: One fermentation was started with $50 \mathrm{~g} / \mathrm{L}$ of additional starting glucose (i.e. extra glucose addition at $\mathrm{t}=\mathrm{Oh}$ ), other fermentations received a continuous glucose feed of $4 \mathrm{~g} / \mathrm{L}-\mathrm{h}$ (to a total of $50 \mathrm{~g} / \mathrm{L}$ glucose w.r.t. initial volume) initiated at $12 \mathrm{~h}, 30 \mathrm{~h}$, or $43 \mathrm{~h}$. These time points were selected as they were approximately the start of the linear production phase, the end of linear production phase and near the end of the fermentation (glucose $<10 \mathrm{~g} / \mathrm{L}$ ). Bolus addition was tested with two boluses of $25 \mathrm{~g} / \mathrm{L}$ (w.r.t. initial volume) of dry glucose added at $20 \mathrm{~h}$ and $30 \mathrm{~h}$. In all vessels the fumarate selectivity decreased after the glucose feed was started, resulting in lower productivities and yields. . Glucose feeds resulted in decreased fumarate production and an increase in malic acid and glycerol co-products. Use of glucose boluses rather than a continuous feed, gave relatively high productivity and titer, which suggesting that glucose boluses work better than a continuous feed (Table 4).

Fed-batch: Effect of higher initial nitrogen concentration. To improve the productivity in fed-batch fermentations, the amount of $\left(\mathrm{NH}_{4}\right)_{2} \mathrm{SO}_{4}$ was increased by $50 \%$ to increase biomass and increase the productivity of fumarate. Phosphate was also increased to maintain the N/P ratio at 1.05. Glucose was added as a bolus when residual glucose was $<10 \mathrm{~g} / \mathrm{L}$. Fumarate productivity increased to $1.6 \mathrm{~g} / \mathrm{L}$.h, and yield was maintained at $54.4 \%$ ( $0.54 \mathrm{~g}$ fumarate/g glucose) (Table 4$)$. All fed-batch fermentations exhibited a decreased fumarate/malate ratio after the glucose feed was initiated. Although increased initial nitrogen improved the productivity in fed-batch fermentations, the fed-batch mode overall had lower productivity than batch fermentations. The marginal increase in yield did not compensate for the loss of productivity in fumarate manufacturing costs. 
Table 4: Effect feed strategy on fumaric acid fermentation performance. In all vessels $50 \mathrm{~g} / \mathrm{L}$ glucose was added, either as a continuous feed or as a bolus. Glucose feed rate was $4 \mathrm{~g} / \mathrm{L}$.h (where applicable).

\begin{tabular}{|l|l|l|l|l|l|l|}
\hline $\begin{array}{l}\text { Initial glucose } \\
\text { concentration } \\
(\mathrm{g} / \mathrm{L})\end{array}$ & $\begin{array}{l}\text { Glucose } \\
\text { feed } \\
\text { started } \\
\text { at EFT }(\mathrm{h})\end{array}$ & $\begin{array}{l}\left(\mathrm{NH}_{4}\right)_{2} \mathrm{SO}_{4} \\
\text { conc (g/L) }\end{array}$ & $\begin{array}{l}\text { FA } \\
\text { Titer } \\
(\mathrm{g} / \mathrm{L})\end{array}$ & $\begin{array}{l}\text { Yield } \\
\text { g/ } \\
\text { g-glu })\end{array}$ & $\begin{array}{l}\text { Productivi } \\
\text { ty (g/L.h) }\end{array}$ & Glycerol (g/L) \\
\hline 210 & - & $\begin{array}{l}2.16 \\
(20 \% \uparrow)\end{array}$ & 93.6 & 0.515 & 1.09 & 25.5 \\
\hline 160 & 12 & $\begin{array}{l}2.16 \\
(20 \% \uparrow)\end{array}$ & 87.9 & 0.520 & 1.00 & 25 \\
\hline 160 & 30 & $\begin{array}{l}2.16 \\
(20 \% \uparrow)\end{array}$ & 88.4 & 0.520 & 1.05 & 25 \\
\hline 160 & 43 & $\begin{array}{l}2.16 \\
(20 \% \uparrow)\end{array}$ & 79.7 & 0.480 & 1.02 & 26.5 \\
\hline 160 & $\begin{array}{l}20 / 30 \\
\text { Bolus }\end{array}$ & $\begin{array}{l}2.16 \\
(20 \% \uparrow)\end{array}$ & 93.3 & 0.530 & 1.24 & 26.5 \\
\hline 160 & $\begin{array}{l}35 \\
\text { Bolus }\end{array}$ & $\begin{array}{l}2.7 \\
(50 \% \uparrow)\end{array}$ & 92.2 & 0.544 & 1.60 & 25 \\
\hline
\end{tabular}

* Suffered $\mathrm{pH}$ upset in fermentation

Reuse of biomass in fumaric acid fermentation. The feasibility of recycling biomass to extend the acid production phase of the fermentation and improve fermentation yield was evaluated. The strategy was to employ a scheme, where the majority of the fermentation broth (containing product) was removed, while retaining the biomass in the fermentor. Fresh medium (glucose + minerals) was added to the retained biomass to continue the fumaric fermentation. Initially, several perforations were drilled into a dip tube, which was longer than the sparge tube and extended to the bottom of the fermentor. The total area of drilled holes of the tube was $3.07 \mathrm{~cm}^{2}$. A 100 mesh nylon filter was fitted over the tube. The modified filter tube was fitted to the fermentor prior to autoclaving. During the fermentation, 1 L/min air was sparged through the tube to avoid fouling. To minimize adverse effects on the biomass, the filtration was initiated, when the residual glucose concentration was $20 \mathrm{~g} / \mathrm{L}$. At this stage the cells were in a linear acid production phase and would not run out of nutrients during filtration. A pneumatic pump was used for the filtration, which alternated forward and reverse-pumping to de-clog the mesh filter. The filtration rate the rate decreased with time and took $4 \mathrm{~h}$ to filter out $3.7 \mathrm{~L}$ of broth. Filtration was stopped after $4 \mathrm{~h}$, and $3 \mathrm{~L}$ of fresh media containing $100 \mathrm{~g} / \mathrm{L}$ glucose and standard amounts of minerals added. The fermentation proceeded until all the glucose was consumed. Unlike previous fedbatch fermentations, there was no significant decrease in productivity. The interval yield (after medium replacement) was $\approx 58 \%$ (Table 5 ). A second addition of $3 \mathrm{~L}$ of glucose + minerals was performed at $61 \mathrm{~h}$ and the fermentation continued with a yield of $59 \%$ and maintained the glucose consumption rate.

It appeared that the yield could be improved by recycling the fungal biomass. Recycling of biomass without using external filtration units (as attempted in this study) should be possible, but a better filtration design that offers higher filtration area and prevents membrane fouling would be required. This study indicated that yield and productivity may be improved in fed-batch fermentations by using glucose + minerals-feed, rather than a glucose-only feed. 
Table 5: Progression of fermentation \# 30711. DO set point was $100 \%$ (controlled by agitation within

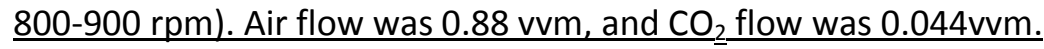

\begin{tabular}{|c|c|c|}
\hline EFT interval (h) & FA yield (g-fa/g-glu) & FA productivity (g/l.h) \\
\hline $0-38.5$ & $0.49 *$ & 1.45 \\
\hline \multicolumn{3}{|l|}{$\begin{array}{l}\text { 3.7L broth filtered, } \\
\text { 3L fresh media added }\end{array}$} \\
\hline $43-61$ & 0.58 & 1.18 \\
\hline \multicolumn{3}{|c|}{ 3.1L fresh media added } \\
\hline $61-86.8$ & 0.59 & $1.10^{\ddagger}$ \\
\hline
\end{tabular}

* Lower yield was attributed to formation of higher amount of ethanol.

" Ignores dilution due to media addition but corrects for dilution achieved by adding the equal amount of sugar as $80 \%$ solution.

Fermentation process scale-up. The laboratory scale fermentation process for the production of fumaric acid was scaled to $2000 \mathrm{~L}$. This volume is considered more representative of commercial production and gives a higher degree of confidence around the scalability of the process.

Initial laboratory scale fermentations were inoculated using a two stage seed train; a spore plate followed by shake flask germination stage. Although this seed train was sufficient to support the required $5 \%(\mathrm{v} / \mathrm{v})$ inoculation required for laboratory scale fermentors it was not appropriate for commercial scale bio-fumaric acid production.

To support larger production tanks a third seed stage was incorporated into the seed train to allow volume and biomass build up for inoculation of a $2000 \mathrm{~L}$ pilot scale production fermentor. The third stage seed fermentation medium was similar to that used in the seed germination flasks except that the glucose concentration was increased to $160 \mathrm{~g} / \mathrm{L}$ and the $\mathrm{MgCO}_{3}$ was omitted from the medium in exchange for $0.05 \mathrm{vvm} \mathrm{CO}_{2}$ in the sparge gas and $\mathrm{Mg}(\mathrm{OH})_{2}$ as the base. A $5 \% \mathrm{v} / \mathrm{v}$ seed was used to inoculate the production vessel using the transfer criteria based on nitrogen exhaustion, which was conveniently detected by a sudden increase in culture $\mathrm{DO}_{2}$.

At pilot scale the agitation rate was adjusted to provide equivalent tip speed (in both the $2000 \mathrm{~L}$ and the $5 \mathrm{~L}$ fermentors) to align the shear-forces in the production tanks. The scaled up fermentation process at $2000 \mathrm{~L}$ demonstrated performance equivalent (within 10\%) of that achieved with the laboratory scale process (Table 6). The volumetric productivity of fumaric acid was higher in the pilot scale vessel than in the lab scale vessel; however this increase was accompanied by a small decrease in yield. This result was attributed to the presence of higher initial concentration of nitrogen in medium prepared at pilot scale. 
Table 6. Comparison of laboratory scale and pilot scale fumaric acid fermentation process

\begin{tabular}{|l|c|c|c|c|c|c|c|}
\hline Scale & $\begin{array}{c}\text { End of } \\
\text { Fermentat } \\
\text { ion } \\
\text { (h)* }\end{array}$ & $\begin{array}{c}\text { Nitrogen } \\
\text { exhaustion, } \\
\text { post } \\
\text { inoculum } \\
\text { (h) }\end{array}$ & $\begin{array}{c}\text { Fumaric } \\
\text { acid titer } \\
\text { (g/l) }\end{array}$ & $\begin{array}{c}\text { Fumaric } \\
\text { Acid Yield } \\
\text { (g/g } \\
\text { glucose) }\end{array}$ & $\begin{array}{c}\text { Productivity } \\
\text { (g fumaric } \\
\text { acid/L.h) }\end{array}$ & $\begin{array}{c}\text { Fumaric } \\
\text { acid } \\
\text { (\% total } \\
\text { organic } \\
\text { acid) }\end{array}$ & $\begin{array}{c}\text { Malic acid } \\
\text { organic } \\
\text { acids) }\end{array}$ \\
\hline $5 \mathrm{~L}$ & 58 & 6 & 77.0 & 0.58 & 1.32 & 71 & 16 \\
\hline $2000 \mathrm{~L}$ & 52 & 8 & 70.1 & 0.53 & 1.42 & 70 & 17 \\
\hline
\end{tabular}

*determined as time of glucose depletion

Although the $\mathrm{DO}_{2}$ set point for all fermentors was $80 \%$ saturation, this level was not maintained in the fermentors with the maximum agitation and sparge rates specified. In lab scale seed fermentors the $\mathrm{DO}_{2}$ decreased to $\approx 40 \%$ saturation (at maximum agitation), this $\mathrm{DO}_{2}$ minimum coinciding with the depletion of the nitrogen source. The $\mathrm{DO}_{2}$ minimum was utilized as a transfer criterion for the seed cultures. In lab scale production vessels the $\mathrm{DO}_{2}$ dropped to $\approx 60 \%$ at nitrogen exhaustion and $\mathrm{DO}_{2}$ increased to $\approx 75 \%$ for the rest of the fermentation period (data not shown).

In the pilot scale runs ( $100 \mathrm{~L}$ seed and $2000 \mathrm{~L}$ production fermentor) the trends observed were similar, but lower minimum $\mathrm{DO}_{2}$ were observed. In the $100 \mathrm{~L}$ seed fermentor the $\mathrm{DO}_{2}$ decreased to $\approx 20 \%$ saturation after $10 \mathrm{~h}$ and remained at this level until $13 \mathrm{~h}$, when it increased. In the $2000 \mathrm{~L}$ production tank the $\mathrm{DO}_{2}$ decreased to $<60 \%$ saturation at the time of nitrogen exhaustion, then increased to $\approx 70 \%$ saturation for the remainder of the fermentation (data not shown).

Fumaric acid separation and purification. Due to the high solubility of the magnesium salt of fumaric acid and the relative insolubility of the free acid, the separation of fumaric acid from the whole fermentation broth was simple and efficient. Filtration of the broth at a $\mathrm{pH}$ above the second $\mathrm{pk}_{\mathrm{a}}$ of fumaric acid $\left(\mathrm{pk}_{\mathrm{a} 1}=3.03, \mathrm{pk}_{\mathrm{a} 2}=4.44\right.$ at $\left.18^{\circ} \mathrm{C}\right)$ separated the biomass and other fermentation solids from the soluble $\mathrm{Mg}$ fumarate product. Recovery of the free acid was then achieved by chilling and acidifying the cell free culture broth to $\mathrm{pH}$ 2.2. At this $\mathrm{pH}$ the free acid of fumaric acid precipitated and was recovered by filtration.

At laboratory scale the filtration of the culture broth was carried out at a temperature of $4^{\circ} \mathrm{C}$ and without $\mathrm{pH}$ adjustment. The broth filtered well and subsequent acidification and mixing for a minimum of $4 \mathrm{~h}$ resulted in $>90 \%$ recovery of the fumaric acid in the fermentation broth (Table 7). The resultant fumaric acid crystals were washed with approximately $40 \%$ of the initial volume of $\mathrm{dH}_{2} \mathrm{O}(700 \mathrm{~mL}$ for 2.9 $L$ of initial fermentation broth) and this resulted in crystals that were $96 \%$ chemically pure fumaric acid.

When the process was scaled to $2000 \mathrm{~L}$ minor adaptations to the downstream processing were required. Laboratory scale testing identified filtration media compatible with the Komline Sanders RDVF for biomass removal ( 515 Komline Sanders), and a different filtration medium for subsequent fumaric acid crystal recovery (K-S 2019, Komline Sanders). Although the 515 cloth was effective in the removal of fungal hyphae from the fermentation broth at laboratory scale, the same cloth blinded and the filtration rate decreased significantly, when used at pilot scale on the RDVF. Testing identified that blinding was caused by a fine precipitate of $\mathrm{MgCO}_{3}$ forming in the weave of the filter cloth. In the pilot scale 
fermentor, $\mathrm{MgCO}_{3}$ was maintained in a soluble form (as $\left.\mathrm{Mg}\left(\mathrm{HCO}_{3}\right)_{2}\right)$ due to the $\mathrm{CO}_{2}$ saturation of the medium and the increased hydrostatic pressure in the larger vessel. Rapid removal of $\mathrm{CO}_{2}$ during the filtration step and the pressure drop across the filtration medium resulted in formation of insoluble $\mathrm{MgCO}_{3}$ within the weave of the cloth. To overcome this issue the chilled (to $11^{\circ} \mathrm{C}$ rather than $4^{\circ} \mathrm{C}$ due to cooling capacity constraints at pilot scale) fermentation broth was adjusted to a pH of $4.2, w^{2}$ ith $\mathrm{H}_{2} \mathrm{SO}_{4}$. This acidification was sufficient for removal of the excess $\mathrm{CO}_{2}$ in the fermentation broth, thereby preventing the blinding of the cloth, while maintaining the fumaric acid in the soluble (salt) form and led to a faster filtration of broth for removal of biomass and other insoluble components.

Subsequent acidification of the cell free fermentation beer to 2.3 (with $\mathrm{H}_{2} \mathrm{SO}_{4}$ ) formed a fumaric acid precipitate that was recovered using the RDVF as predicted. Fumaric acid crystal-containing broth was filtered at a rate of approximately $400 \mathrm{~kg} / \mathrm{h}$ and the retained crystals were washed as they were recovered with water at a rate of $1.8 \mathrm{~L} / \mathrm{min}$. Analysis of the fumaric acid obtained from the pilot scale fermentor demonstrated that the product was similar to that obtained from the laboratory scale process, $>95 \%$ chemically pure initially and being recovered with an efficiency of $92 \%$ (Table 7 ). Further washing and more complete drying of the fumaric acid crystals produced a final preparation with $97.5 \%$ chemical purity, albeit at a decreased recovery efficiency of approximately $85 \%$. The remaining $2.5 \%$ was composed of $0.5 \%$ ash and $2.0 \%$ other organic acids, including succinic acid and malic acid. Lower recovery at pilot scale was due to a single batch being processed, resulting in losses associated with hold up of fermentation broth in hosing and processing equipment.

Table 7. Recovery and purification of fumaric acid from fermentation broth

\begin{tabular}{|c|c|c|c|c|c|c|c|c|c|}
\hline \multirow[t]{2}{*}{ Scale } & \multicolumn{3}{|c|}{ Fermentation broth } & \multicolumn{3}{|c|}{ Mother liquor } & \multicolumn{3}{|c|}{ Collected solid } \\
\hline & $\begin{array}{c}\text { Volume } \\
\text { (I) }\end{array}$ & $\begin{array}{l}\text { Fumaric } \\
\text { Acid } \\
(\mathrm{g} / \mathrm{l})\end{array}$ & $\begin{array}{l}\text { Fumaric } \\
\text { acid } \\
\text { (g) }\end{array}$ & $\begin{array}{l}\text { Volume } \\
\text { (I) }\end{array}$ & $\begin{array}{c}\text { Fumaric } \\
\text { Acid } \\
(\mathrm{g} / \mathrm{l})\end{array}$ & $\begin{array}{l}\text { Fumaric } \\
\text { Acid } \\
\text { (g) }\end{array}$ & $\begin{array}{l}\text { Fumaric } \\
\text { Acid } \\
\text { (g) }\end{array}$ & $\begin{array}{c}\text { Fumaric } \\
\text { Acid } \\
\text { purity } \\
\text { (\%) }\end{array}$ & $\begin{array}{c}\text { Recovery } \\
\text { (\%) }\end{array}$ \\
\hline $\begin{array}{l}\text { Lab scale } \\
\qquad(<10 \text { L) }\end{array}$ & 2.9 & 58.8 & 70.5 & 3.5 & 3.2 & 11.4 & 157.5 & 96.3 & 92.4 \\
\hline $\begin{array}{c}\text { Pilot } \\
\text { Scale } \\
\text { (2000 L) }\end{array}$ & 2518 & 59.6 & 50100 & 3310 & 3.3 & 1000 & 137000 & 96.9 & 88.5 \\
\hline
\end{tabular}

Fumaric acid production by fermentation. The literature indicated that to achieve high titers of fumaric acid it was necessary to use calcium hydroxide as the base (Zhou et al., 2002). Unfortunately this creates problems for both the fermentation and the recovery, related to the insoluble nature of the calcium fumarate.

MBI discovered discovered that under the correct conditions high titers of fumaric acid could also be achieved when $\mathrm{Mg}(\mathrm{OH})_{2}$ or magnesium carbonate were used to maintain the $\mathrm{pH}$ of the fermentation. Many of the fermentation and downstream issues associated with using $\mathrm{CaCO}_{3}$ could be eliminated if 
$\mathrm{Mg}(\mathrm{OH})_{2}$ or magnesium carbonate was used as the base during fermentation, since magnesium fumarate has a solubility of over $100 \mathrm{~g} / \mathrm{L}$.

A first step in any recovery procedure for many organic acids is the removal of insoluble impurities, cells, and cell debris from the broth prior to further processing. In previous work (with A. succinogenes), diafiltration through a membrane filter was required to clarify the broth. However the fumaric acid fermentation used a cleaner medium, which in combination with the production organism being a filamentous fungus, eliminated the need for tangential dia-filtration. Particulates, cells and cell debris could be removed from the fermentation broth by vacuum filtration through a layer of Celite. Subsequent acidification with $\mathrm{H}_{2} \mathrm{SO}_{4}$ precipitated the fumaric acid while the $\mathrm{MgSO}_{4}$ formed was soluble allowing the fumaric acid to be collected by filtration. Initial experiments using this process gave a recovery yield of $84 \%$ with $3 \%$ fumaric acid left in the mother liquor.

Mass Balance. Achieving only an $87 \%$ mass balance was unexpected. Upon investigation it was discovered that when cells where not promptly removed from the broth at the end of the fermentation fumaric acid was converted to malic acid. It was possible that fumarate hydratase liberated from cells remained active with the reaction favoring malic acid in the aqueous media.

Fumaric acid was recovered from $2 \mathrm{~L}$ and $5 \mathrm{~L}$ of fermentation broth from which cells had been promptly removed. The recovered acid from the $2 \mathrm{~L}$ sample had a chemical purity of $94.8 \%$ after collection and drying. The yield for the recovery process was $96.3 \%$, with $2.3 \%$ remaining in the mother liquor (a mass balance of $98.6 \%)$. For the $5 \mathrm{~L}$ sample the recovered acid had a chemical purity of $94.0 \%$ after collection and drying. The yield for the recovery process was $96.4 \%$, with $3.1 \%$ in the mother liquor (a mass balance of $99.5 \%)$.

Mineral Impurities. An unexpected consequence of the use of Celite in the filtration was the introduction of unwanted cations. Mineral analysis of the fumaric acid recovered from broth filtered through Celite revealed higher levels of a variety of cations than anticipated, particularly calcium, which was not used in the fermentation. Attempts were made to decrease the level of impurities by washing the crude product with increasing amounts of water. The results are summarized in Table 8. 
Table 8: Mineral analysis of organic acid A recovered with and without the use of Celite. Mineral contents were determined by ICP-AES

\begin{tabular}{|l|c|c|c|c|c|c|c|}
\hline Sample Name & Calcium & Iron & Potassium & Sodium & Phosphorous & Sulfur & $\begin{array}{c}\text { Wash } \\
\text { water } \\
(\mathrm{mL})\end{array}$ \\
\hline Processed using Celite & & & & & \\
\hline GT-940-60B & 76.2 & 12.7 & 154 & 21.7 & 92.4 & 15104 & 3 \\
\hline GT-940-60C & 84.9 & 8.41 & 138 & 39.4 & 51.6 & 8541 & 60 \\
\hline GT-940-60D & $<50.0$ & $<5.0$ & 67.4 & 35.9 & 23.3 & 1247 & 120 \\
\hline GT-940-60E & $<50.0$ & $<5.0$ & 66.8 & 31.5 & 30.1 & 1200 & 180 \\
\hline MBI 918-37 & $<50.0$ & 5.72 & $<50.0$ & $<20.0$ & $<20.0$ & 987 & 180 \\
\hline Processed without Celite \\
\hline RJH918-41-B & $<50.0$ & $<5.0$ & $<50.0$ & $<20.0$ & $<20.0$ & 141 & 120 \\
\hline RJH918-41-A & $<50.0$ & $<5.0$ & $<50.0$ & $<20.0$ & $<20.0$ & 338 & 120 \\
\hline
\end{tabular}

Washing decreased the amount of contaminating ions, however since the source of the contaminating ions was the Celite used in the recovery process, alternative filtration procedures were evaluated. A filter cake of the biomass developed on filter cloth or felt, during biomass removal, and acted like a depth filter. As a result the filtration became more efficient as it progressed. The filtrate was recycled through the filter cake until a sufficiently clarified solution was obtained. The mineral analysis of fumaric acid recovered from broth clarified without using Celite was obtained (Table 8).

\section{pH for precipitation}

A key cost in the production of organic acids by fermentation is the mineral acid used to convert the salt formed in the fermentation to the free acid. Several experiments where performed to determine the effect of different amounts of acid on the recovery yield and product purity. Data suggested reduced recovery with increasing $\mathrm{pH}$, however a high degree of experimental variation was observed and there was no statistical difference in the recovery yield or product purity over the $\mathrm{pH}$ range tested (data not shown)

The recovery process was modeled using CurTiPot to predict the recovery yield based on the organic acid salt distribution using different amounts of $\mathrm{H}_{2} \mathrm{SO}_{4}$ to acidify the solution (Figure 4). The model suggested no significant reduction in yield over the range of acid addition tested. Based on the modeling data another series of experiments were performed over a wider range of $\mathrm{pH} /$ acid additions (Figure 4). There was good agreement between the model predictions and the experimental data, which show recovery yields decreased significantly with decreasing mineral acid addition only when less than 1.4 equivalents of $\mathrm{H}_{2} \mathrm{SO}_{4}$ was used compared to the amount of fumaric acid. The purity of the recovered acid was not affected (Figure 4). 


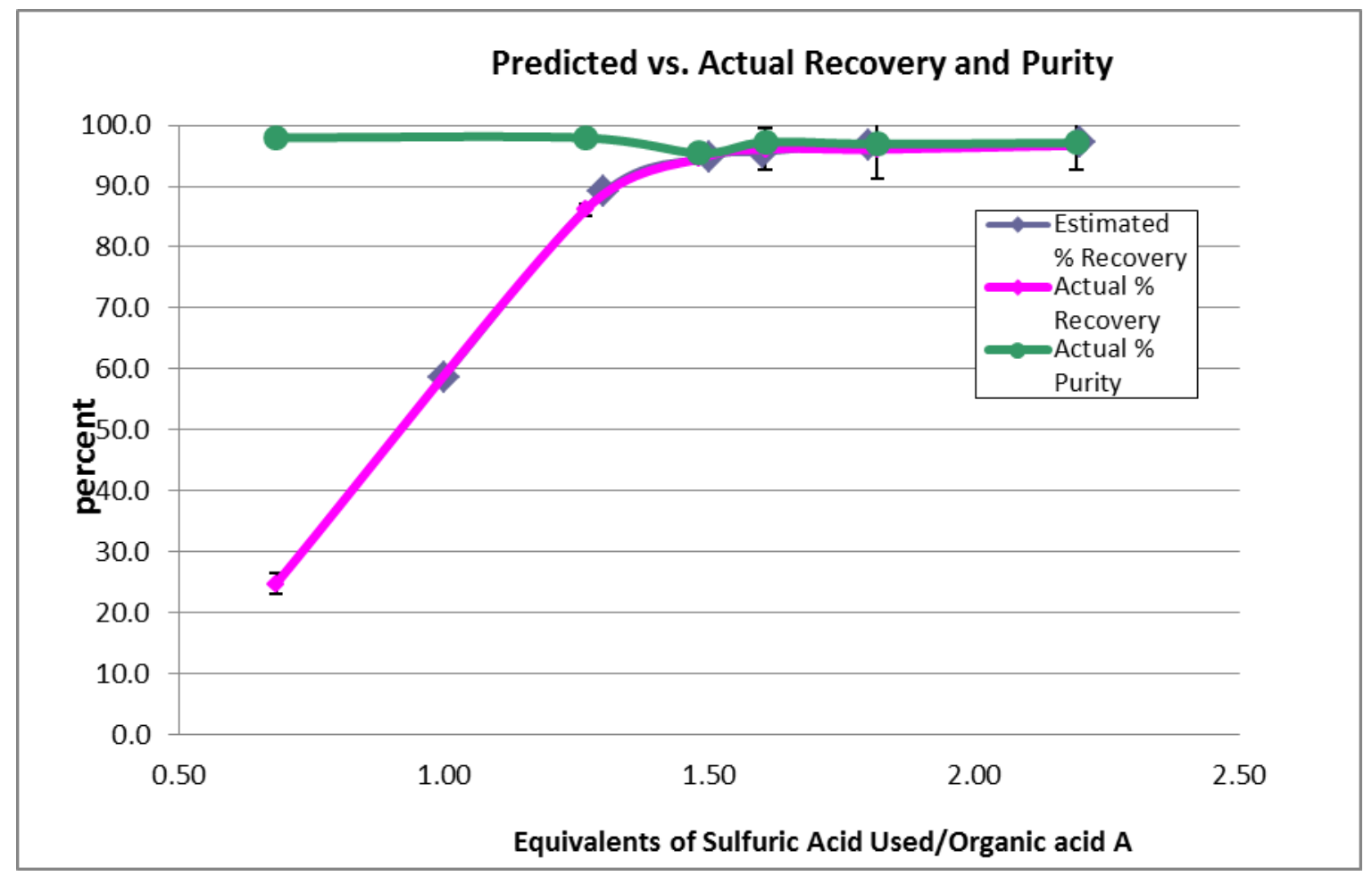

Figure 4: Recovery yields and purity of fumaric acid obtained using different amount of $\mathrm{H}_{2} \underline{\mathrm{SO}}_{4}$.

Temperature for fumaric acid precipitation. Fumaric acid currently sold into an initially targeted niche market has a slightly higher purity than obtained using the MBI process. In an attempt to meet the required specifications, the effect the temperature of acidification-precipitation on the purity and recovery yield was tested.

The temperature of the clarified broth was adjusted and $\mathrm{H}_{2} \mathrm{SO}_{4}$ was slowly added to acidify the broth to a pH of $2.0 \pm 0.3$. The addition of the acid was exothermic and increased the temperature of the broth dependent on the rate of acid addition and whether cooling was applied. After addition of the acid, and cooling the broth, the solid was collected by vacuum filtration and rinsed with cold water (Table 9). The results from a scale up recovery are included for comparison. 
Table 9: Effect of temperature on fumaric acid purity and recovery yield

\begin{tabular}{|l|c|c|c|c|c|c|}
\hline $\begin{array}{l}\text { Experiment } \\
\#\end{array}$ & $\begin{array}{c}\text { Starting } \\
\text { temperature, } \\
\left({ }^{\circ} \mathrm{C}\right)\end{array}$ & $\begin{array}{c}\text { Temperature } \\
\text { after acid } \\
\text { addition, }\left({ }^{\circ} \mathrm{C}\right)\end{array}$ & $\begin{array}{c}\text { Collection } \\
\text { temperature, } \\
\left({ }^{\circ} \mathrm{C}\right)\end{array}$ & $\begin{array}{c}\text { fumaric } \\
\text { acid purity } \\
(\% \mathrm{w} / \mathrm{w})\end{array}$ & $\begin{array}{c}\text { succinic } \\
\text { acid in } \\
\text { Recovery } \\
\text { yield \% }\end{array}$ & $\begin{array}{c}\text { (ample }(\% \\
\mathrm{w} / \mathrm{w})\end{array}$ \\
\hline $\begin{array}{l}\text { Scale up } \\
\text { run }\end{array}$ & 14 & 20 & 14 & 98.2 & $\mathrm{a}$ & 0.8 \\
\hline 1 & 10 & 12 & 12 & 92.0 & 92.9 & 2.3 \\
\hline 2 & 10 & 35 & 35 & 93.8 & 86.3 & 1.3 \\
\hline 3 & 12 & 40 & 2 & 93.7 & 94.6 & 1.4 \\
\hline 4 & 40 & 61 & 60 & 98.3 & 72.0 & 0.5 \\
\hline 5 & 40 & 62 & 60 & 97.5 & 76.0 & 0.5 \\
\hline 6 & 40 & 60 & 60 & 98.6 & 67.1 & 0.5 \\
\hline 7 & 67 & 70 & 68 & 97.5 & 65.3 & 0.3 \\
\hline 8 & 45 & 55 & 4 & 98.8 & 90.9 & 0.6 \\
\hline 9 & 40 & 56 & 4 & 99.2 & 93.3 & 0.6 \\
\hline 10 & 40 & 60 & 4 & 98.0 & 90.2 & 0.5 \\
\hline 11 & 45 & 64 & 4 & 99.0 & 93.1 & 0.6 \\
\hline
\end{tabular}

a- Due to equipment problems an accurate recovery yield is not available

It was assumed that acidification at a lower temperature would result in a product with higher purity. The experimental results did not support this hypothesis. Instead lower temperature resulted in a product with lower chemical purity compared to experiments at higher temperatures (Table 9). The amount of succinic acid was notably higher for all laboratory experiments run at lower temperatures. The recovery yield correlated well with the temperature of the crystals collection. Contrary to expectation the highest purity was obtained when an elevated temperature was used (Table 9). Further replicate experiments were performed and confirmed these findings (data not shown).

Although filtration of fermentation broth through cloth removed most solids, fine solids passed through the cloth filter, resulting in a slightly cloudy filtrate (even after recycling the broth). Removal of these fine solids was tested to establish if increased product purity was achieved. A nylon filter with a smaller pore size was used, which gave a clear filtrate. No increase in purity was observed. Based on the data generated it appeared that the use of a filtration cloth, a starting temperature of $40^{\circ} \mathrm{C}$, collection temperature of $4^{\circ} \mathrm{C}$ gave the best overall performance, balancing product purity and recovery yield.

The purity obtained from the conditions described still resulted in a chemical purity below the purity specification of fumaric acid. Higher volumes in commercial production may achieve the required standards for fumaric acid, since higher volumes will involve slow acid addition and slow cooling, which should increase the purity..

Purification of fumaric acid

The purity of fumaric acid recovered using the MBI procedure varied from $94-98 \%$ chemical purity, with the best conditions achieving a purity of $98.3 \pm 0.6 \%$, below the $99 \%$ typical available from commercial 
sources. One method to improve the chemical purity would be to prepare the di-ester, distill and then hydrolyze the fumarate ester back to the free acid as shown in Figure 4.

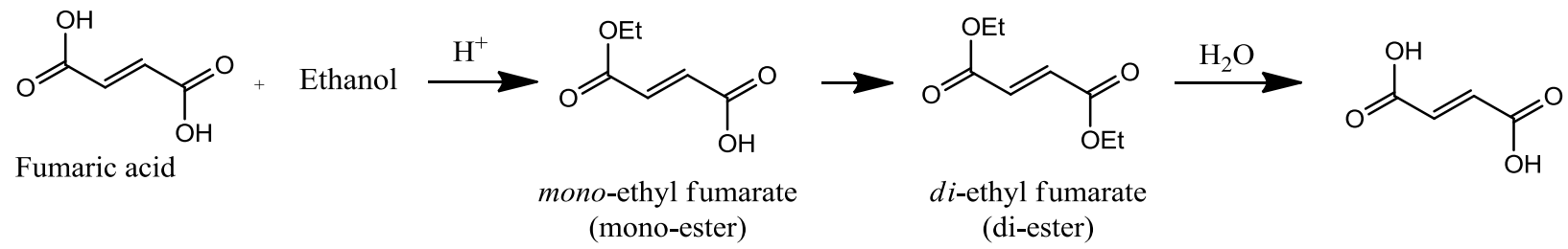

Figure 4: Reaction schematic for the esterification of fumaric acid with ethanol

Esterification protocols were previously established for succinic acid that achieved a $97.5 \%$ conversion to the di-ester at bench scale. Losses of $5 \%$ occurred during distillation, when water and excess alcohol were removed from the reaction. The di-ester co-distilled with the water/alcohol mixture. To determine the viability of converting the fumaric acid to its ester as an approach to further purification, the same protocol was tested using commercially obtained fumaric acid. The esterification reaction was completed, and $\mathrm{Na}_{2} \mathrm{CO}_{3}$ added to neutralize the mineral acid used as the catalyst. Unfortunately, this formed a fine precipitate that was difficult to remove, requiring multiple filtrations and unacceptable loss of product. In subsequent experiments the acid catalyst was neutralized using IRA 96, a weak base anion exchange resin, which is easily removable by filtration. This achieved a $95 \%$ recovery of the diester product, similar to succinic acid where $2 \%$ of the product co-distilled with the ethanol/water mixture. Two percent of fumaric acid also remained as the intermediate mono-ester. This experiment indicated that purification of fumaric acid through the di-ester is a viable purification technique, but is subject to comparable losses to succinic acid.

\section{Conversion of malic acid to fumaric acid}

The fermentation process for fumaric acid generated malic acid as a co-product at approximately $20 \%$ of the titer of fumaric acid, which constituted a significant loss of carbon. The chemical conversion of malic acid to fumaric acid is known and could be performed post-fermentatively. In the chemical conversion, the equilibrium is driven to the formation of fumaric acid by removing water from the reaction mixture as it is formed. The conversion of malic acid to fumaric acid in mother liquors after the bulk of the fumaric acid had been recovered was investigated.

Chemical conversion of malic to fumaric acid required the presence of a strong acid catalyst. Some excess $\mathrm{H}_{2} \mathrm{SO}_{4}$ was needed to convert remaining carboxylate salts to their free acid forms and to act as the acid catalyst for the chemical conversion. The use of different amount of sulfuric acid was evaluated. After acidification, the liquor was concentrated then subjected to conditions favoring the desired chemical transformation (Table 10). 
Table 10: Results of chemical conversion of by-product to co-product in mother liquor

\begin{tabular}{|c|c|c|c|c|c|c|c|c|}
\hline \multirow[b]{2}{*}{ Entry } & \multirow[b]{2}{*}{$\begin{array}{c}\mathrm{H} 2 \mathrm{SO} 4, \\
\text { Amount } \\
\text { used/Amount } \\
\text { Estimated }\end{array}$} & \multirow{2}{*}{\begin{tabular}{|c|} 
Starting \\
\\
By-product \\
(mol) \\
\end{tabular}} & \multicolumn{3}{|c|}{ Recovered } & \multicolumn{2}{|c|}{ Residue } & \multirow[b]{2}{*}{$\begin{array}{c}\text { Mass } \\
\text { balance } \\
\% \\
\end{array}$} \\
\hline & & & $\begin{array}{c}\text { By- } \\
\text { Product } \\
\text { (mol) }\end{array}$ & $\begin{array}{c}\text { Co- } \\
\text { Product } \\
\text { (mol) }\end{array}$ & $\begin{array}{c}\text { Recovered } \\
\text { Yield\% }\end{array}$ & $\begin{array}{c}\text { By- } \\
\text { Product } \\
\text { (mol) }\end{array}$ & $\begin{array}{c}\text { Co- } \\
\text { Product } \\
\text { (mol) }\end{array}$ & \\
\hline 1 & 3.0 & 0.157 & 0.001 & 0.13 & $83 \%$ & 0.035 & 0.022 & $103 \%$ \\
\hline 2 & 1.0 & 0.239 & 0.003 & 0.16 & $69 \%$ & 0.022 & 0.033 & $82 \%$ \\
\hline 3 & 1.3 & 0.190 & 0.001 & 0.13 & $67 \%$ & 0.022 & 0.042 & $85 \%$ \\
\hline 4 & 1.1 & 0.120 & 0.001 & 0.07 & $55 \%$ & 0.022 & 0.046 & $100 \%$ \\
\hline 5 & 1.9 & 0.081 & 0.000 & 0.04 & $52 \%$ & 0.021 & 0.026 & $83 \%$ \\
\hline 6 & 1.6 & 0.174 & 0.002 & 0.08 & $46 \%$ & 0.051 & 0.037 & $86 \%$ \\
\hline 7 & 1.3 & 0.186 & 0.003 & 0.08 & $41 \%$ & 0.025 & 0.044 & $71 \%$ \\
\hline 8 & 2.7 & 0.174 & 0.001 & 0.12 & $70 \%$ & 0.023 & 0.028 & $88 \%$ \\
\hline
\end{tabular}

Only catalytic amounts of acid should be required for the by-product conversion. However, it was found a 3 -fold excess of acid gave the best results, a recovery yield of $83 \%$ (Table 10). The use of such a large excess $\mathrm{H}_{2} \mathrm{SO}_{4}$ would be economical, unless the acid could be recycled. The requirement for a large excess of $\mathrm{H}_{2} \mathrm{SO}_{4}$ was probably the result of the presence of large amounts of $\mathrm{MgSO}_{4}$ in the mother liquor. The addition of $\mathrm{H}_{2} \mathrm{SO}_{4}$ to a solution containing $\mathrm{MgSO}_{4}$ will first result in the formation of magnesium bisulfate.

While magnesium bisulfate is acidic it is too weak to catalyze the conversion of malic to fumaric acid. Therefore, it is only after sufficient $\mathrm{H}_{2} \mathrm{SO}_{4}$ has been added to convert all the $\mathrm{MgSO}_{4}$ to the bisulfate that there will be $\mathrm{H}_{2} \mathrm{SO}_{4}$ to catalyze the chemical conversion of malic acid to fumaric acid.

Conversion of malic acid to fumaric acid exhibited poor and variable mass balance; presumably due to malic acid undergoing side reactions such as the formation of maleic anhydride, and the formation of an ester with glycerol in the fermentation broth. Although it was possible to convert malic acid formed in the fermentation to fumaric acid the large excess of sulfuric acid required and the low conversion efficiency make the chemical conversion uneconomic unless the acid could be recycled and co-products contained in the mother liquor could be first separated to minimize or avoid side reactions. 


\section{Base Recycle for the fumaric acid fermentation}

In the production of fumaric acid using $\mathrm{Mg}(\mathrm{OH})_{2}$ as the base a mole equivalent of $\mathrm{MgSO}_{4}$ is formed in conversion of magnesium fumarate to the free acid. There is a market for $\mathrm{MgSO}_{4}$ however the conversion of the $\mathrm{MgSO}_{4}$ to $\left(\mathrm{NH}_{4}\right)_{2} \mathrm{SO}_{4}$ with the regeneration of $\mathrm{Mg}(\mathrm{OH})_{2}$ was more attractive since there is a large fertilizer market for $\left(\mathrm{NH}_{4}\right)_{2} \mathrm{SO}_{4}$. Usually a weaker base (such as $\left.\left(\mathrm{NH}_{4}\right)_{2} \mathrm{SO}_{4}\right)$ does not react to form a stronger base (such as $\mathrm{Mg}(\mathrm{OH})_{2}$ ). However due to the low solubility of $\mathrm{Mg}(\mathrm{OH})_{2}$ and the high solubility of $\mathrm{MgSO}_{4}$, it is possible to react $\mathrm{MgSO}_{4}$ with $\mathrm{NH}_{4} \mathrm{OH}$ to form $\left(\mathrm{NH}_{4}\right)_{2} \mathrm{SO}_{4}$, and regenerate $\mathrm{Mg}(\mathrm{OH})_{2}$.

Separation of Magnesium Sulfate. Most inorganic salts are not very soluble in ethanol, in contrast to organic compounds that are produced in the fermentation. A potentially effective method to recover $\mathrm{MgSO}_{4}$, in which the mother liquor was concentrated to a high level of percent solids and the inorganic salt was then precipitated by addition of ethanol was tested (Table 11).

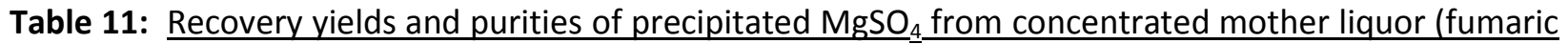
acid recovered)

\begin{tabular}{|l|c|c|c|c|c|c|}
\hline Entry & Broth ID & $\begin{array}{c}\text { Solids in } \\
\text { concentrate } \\
(\% \mathrm{w} / \mathrm{w})^{\mathrm{a}}\end{array}$ & $\begin{array}{c}\text { Ratio } \\
\text { EtOH: } \mathrm{H}_{2} \mathrm{O}\end{array}$ & $\begin{array}{c}\text { Recovery } \\
\text { yield } \\
(\%)\end{array}$ & $\begin{array}{c}\text { Salt purity \% } \\
\text { (minus } \\
\text { water) }\end{array}$ & $\begin{array}{c}\text { Organic acids } \\
(\% \mathrm{w} / \mathrm{w})\end{array}$ \\
\hline 1 & A & 37 & 1.6 & 89.4 & 99.8 & 0.2 \\
\hline 2 & A & 32 & 2.0 & 90.4 & 99.2 & 0.8 \\
\hline 3 & B & 45 & 6.3 & 73.4 & 83.2 & 16.9 \\
\hline 4 & B & 45 & 3.6 & 78.8 & 86.6 & 13.4 \\
\hline 5 & C & 40 & 2.1 & 79.5 & 82.3 & 17.7 \\
\hline 6 & C & 32 & 1.5 & 82.7 & 88.8 & 11.2 \\
\hline 7 & D & 41 & 2.2 & 78.0 & 98.4 & 1.6 \\
\hline 8 & D & 41 & 2.4 & 79.0 & 95.5 & 4.5 \\
\hline
\end{tabular}

a- Solids were calculated based on the assumption that all mineral acid added was converted to its corresponding mineral salt plus residual organic acids.

The efficiency of the isolation of the mineral salt was anticipated to depend primarily on the concentration and the amount of ethanol used compared to the residual water. However, the data obtained did not confirm this and did not reveal a clear trend (data not shown).

Using the same mother liquor (to avoid undue experimental variation) tests were performed to assess, if the purity of the recovered $\mathrm{MgSO}_{4}$ was affected by the $\mathrm{pH}$ after acidification. Attempts were made to minimize $\mathrm{H}_{2} \mathrm{SO}_{4}$ usage, so the fermentation broth was routinely acidified to a pH only slightly below the lower pKa value of fumaric acid, $\sim \mathrm{pH}$ 2.5. This value was sufficient to achieve good recovery yields of fumaric acid, due to the low solubility of the free fumaric acid. In contrast, other organic acid byproducts in the broth remained soluble as free acids or mono-salts. During subsequent steps, these byproducts could precipitate with the, $\mathrm{MgSO}_{4}$, and decrease the purity of the recovered $\mathrm{MgSO}_{4}$. The effect of acidification of broth to $\mathrm{pH}$ values 2.0, 2.3, and 2.5 on $\mathrm{MgSO}_{4}$ purity was tested, (Table 12). Lower $\mathrm{pH}$ values increased the purity of the recovered $\mathrm{MgSO}_{4}$. 
Table 12: Separation of $\mathrm{MgSO}_{4}$ and organic by-products (step A). Recovery yields and purities of precipitated $\mathrm{MgSO}_{4}$ from concentrated mother liquor (post fumaric acid recovery).

\begin{tabular}{|l|c|c|c|c|c|c|}
\hline Line & Broth ID & $\begin{array}{c}\mathrm{pH} \text { of } \\
\text { broth }\end{array}$ & $\begin{array}{c}\text { Solids in } \\
\text { concentrate } \\
(\%)\end{array}$ & $\begin{array}{c}\text { Ratio } \\
\text { EtOH: } \mathrm{H}_{2} \mathrm{O}\end{array}$ & $\begin{array}{c}\text { Recovery } \\
\text { yield } \\
(\%)\end{array}$ & $\begin{array}{c}\text { Salt purity } \\
\text { (\%, minus } \\
\text { water) }\end{array}$ \\
\hline 1 & A & 2.0 & 30 & 2.0 & 101 & 98.5 \\
\hline 2 & A & 2.3 & 30 & 2.0 & 93 & 97.3 \\
\hline 3 & A & 2.5 & 30 & 2.0 & 95 & 94.2 \\
\hline
\end{tabular}

a- Solids were calculated based on the assumption that all mineral acid added was converted to its corresponding mineral salt plus residual organic acids.

The reproducibility of $\mathrm{MgSO}_{4}$ recovery under identical conditions gave purity values of $97.5 \% \pm 1.2 \%$ (data not shown). To reduce the variability and improve the purity the effect of washing on the purity of the recovered mineral salt crystals was tested (Table 13). Additional washing of the $\mathrm{MgSO}_{4}$ improved the chemical purity It is noteworthy that for samples that were precipitated at a $\mathrm{pH}$ of $<2.0$, washing improved the chemical purity to $>99 \%$.

Table 13: $\underline{\text { The effect of washing on purity of recovered } \mathrm{MgSO}_{4}}$

\begin{tabular}{|c|c|c|}
\hline $\begin{array}{l}\text { pH for initial } \\
\text { recovery }\end{array}$ & $\begin{array}{c}\mathrm{MgSO}_{4} \text { purity (before } \\
\text { washing) } \\
(\%)\end{array}$ & $\begin{array}{c}\mathrm{MgSO}_{4} \text { purity (after } \\
\text { washing) } \\
\text { (\%) }\end{array}$ \\
\hline 2.52 & 95.3 & 95.3 \\
\hline 2.48 & 98.3 & 98.9 \\
\hline 2.48 & 96.4 & 98.4 \\
\hline 1.95 & 98.0 & 99.2 \\
\hline 1.98 & 98.5 & 99.3 \\
\hline
\end{tabular}

Regeneration of $\mathrm{Mg}(\mathrm{OH})_{2}$ and formation of $\left(\mathrm{NH}_{4}\right)_{2} \mathrm{SO}_{4}$.

$\mathrm{NH}_{4} \mathrm{OH}$ was added to $\mathrm{MgSO}_{4}$ to from $\left(\mathrm{NH}_{4}\right) \mathrm{SO}_{4}$ and precipitate $\mathrm{Mg}(\mathrm{OH})_{2}$. A matrix consisting of three concentrations of $\mathrm{MgSO}_{4}$ and three concentrations of $\mathrm{NH}_{4} \mathrm{OH}$ were tested. The amount of $\mathrm{Mg}$ precipitated was determined by atomic absorption, by subtraction of the final amount of soluble $\mathrm{Mg}$ after addition of $\mathrm{NH}_{4} \mathrm{OH}$ and filtering from the initial concentration (Table 14)

Table 14: Percentage of $\mathrm{Mg}$ remaining in solution after addition of $\mathrm{NH}_{4} \mathrm{OH}$

\begin{tabular}{|l|c|c|c|}
\hline & \multicolumn{3}{|c|}{$\mathrm{MgSO}_{4}$ concentration (w/v) } \\
\hline $\begin{array}{l}\mathrm{NH}_{4} \mathrm{OH} \text { added (mole } \\
\text { equivalents) }\end{array}$ & $5 \%$ & $10 \%$ & $20 \%$ \\
\hline & \multicolumn{2}{|c|}{ Percentage of Mg remaining in solution } \\
\hline 5 & 28 & 21 & 20 \\
\hline 10 & 12 & 11 & 15 \\
\hline 20 & 11 & 8 & 11 \\
\hline
\end{tabular}


Increasing amounts of $\mathrm{NH}_{4} \mathrm{OH}$ precipitated increasing amounts of $\mathrm{Mg}(\mathrm{OH})_{2}$, consistent with a theoretical evaluation of the reaction equilibrium.

To verify that the solid collected was $\mathrm{Mg}(\mathrm{OH})_{2}$ the base equivalents per gram of solid was determined by titration and compared to authentic $\mathrm{Mg}(\mathrm{OH})_{2}$ (Table 15). Initial samples were collected and dried without rinsing which gave a lower base equivalent/g of solids compared to authentic $\mathrm{Mg}(\mathrm{OH})_{2}$. Rinsing the collected solid prior to drying (to remove excess mother liquor containing a high concentration of dissolved salt) gave base equivalents similar to the authentic $\mathrm{Mg}(\mathrm{OH})_{2}$

Table 15: Base mole-equivalents/g of solid for $\mathrm{Mg}(\mathrm{OH})_{2}$ and solids precipitated with $\mathrm{NH}_{4} \mathrm{OH}$ from a $\mathrm{MgSO}_{4}$ solution.

\begin{tabular}{|l|c|c|c|}
\hline Solid ID & $\begin{array}{c}\text { Equivalents } \\
\mathrm{NH}_{4} \mathrm{OH} \\
\text { used in } \\
\text { recovery }\end{array}$ & Washed & $\begin{array}{c}\text { mEquiv. } \\
\text { Base/g }\end{array}$ \\
\hline $\mathrm{Mg}(\mathrm{OH})_{2}$ & - & - & 35 \\
\hline $44-\mathrm{AS}$ & 5 & no & 19 \\
\hline 44-BS & 10 & no & 23 \\
\hline 44-CS & 20 & no & 25 \\
\hline 50-AS & 20 & yes & 35 \\
\hline $50-B S$ & 10 & yes & 33 \\
\hline
\end{tabular}

Conversion of $\mathrm{MgSO}_{4}$ to $\mathrm{Mg}(\mathrm{OH})_{2}$ using $\mathrm{MgSO}_{4}$ recovered from fermentation broth with a $99 \%$ and $82 \%$ purity, was compared with that of commercial $\mathrm{MgSO}_{4}$ (Table 16).

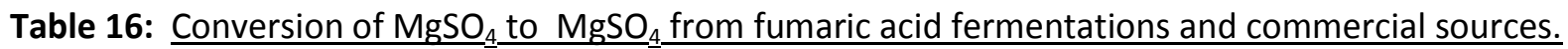

\begin{tabular}{|l|c|c|c|c|}
\hline \multirow{2}{*}{ Starting salt } & \multicolumn{4}{|c|}{ Collected solids } \\
\cline { 2 - 5 } & $\begin{array}{c}\text { Base } \\
\text { Purity } \\
(\%)\end{array}$ & $\begin{array}{c}\text { Percentage of } \\
\text { theoretical } \\
\text { yield }\end{array}$ & $\begin{array}{c}\text { Salt anion in } \\
\text { Solid } \\
(\%)\end{array}$ & autoclaveable \\
\hline $\begin{array}{l}99 \% \text { pure; } \\
<1 \% \text { organic acid }\end{array}$ & 83.4 & 80 & 6 & yes \\
\cline { 2 - 5 } $\begin{array}{l}82 \% \text { pure; } \\
18 \% \text { organic acid }\end{array}$ & 69 & 75 & 12 & yes \\
\cline { 2 - 5 } $\begin{array}{l}99 \% \text { pure; } \\
\text { Commercial grade }\end{array}$ & 45 & 52 & 18 & yes \\
\hline
\end{tabular}

The presence of organic acids resulted in lower yield and lower purity of the recovered $\mathrm{Mg}(\mathrm{OH})_{2}$. Based on these results a target for the purity of recovered $\mathrm{MgSO}_{4}$ of greater $99 \%$ chemical purity was set.

Initial work to recycle $\mathrm{Mg}(\mathrm{OH})_{2}$ focused on the yield and purity of the recovered material. Another important parameter identified during this work was the rheology and behavior of the recovered $\mathrm{Mg}(\mathrm{OH})_{2}$. To be used in subsequent fermentations recovered $\mathrm{Mg}(\mathrm{OH})_{2}$ must form a stable suspension. The initial work demonstrated that many of the suspensions of recovered $\mathrm{Mg}(\mathrm{OH})_{2}$ became unstirrable after autoclaving. 
Recovery and reuse of $\mathrm{Mg}(\mathrm{OH})_{2}$.

$\mathrm{Mg}(\mathrm{OH})_{2}$ was recovered from $20 \mathrm{~L}$ of fermentation broth and tested in subsequent fermentations. Recovered $\mathrm{Mg}(\mathrm{OH})_{2}$ was suspended in water to prepare $\mathrm{a} \approx 12 \mathrm{~N}$ suspension,. However, the consistency of this suspension changed to a semi-solid gel upon prolonged stirring. A more usable suspension was prepared through dilution to a final concentration of $\approx 6 \mathrm{~N}$. A fumaric acid fermentation, in which the $\mathrm{pH}$ was controlled with the recycled base, used the same amount of base as control fermentations (Table 17). The fermentation using the recycled base was slower (i.e. lower productivity) than the control, and had lower yields. Overall, it was established that the base could be recycled with adequate purity for use in fermentation processes, though improvements are required.

Table 18: Fermentations carried out using commercial and recycled $\mathrm{Mg}(\mathrm{OH})_{2}$. DO set point was $100 \%$ (controlled by agitation within $800-900 \mathrm{rpm}$ ). Air flow was $0.88 \mathrm{vvm}$, and $\mathrm{CO}_{2}$ flow was $0.044 \mathrm{vvm}$.

\begin{tabular}{|l|c|c|c|c|c|}
\hline Base & $\begin{array}{c}\text { FA } \\
\text { Titer } \\
\text { (g/L) }\end{array}$ & $\begin{array}{c}\text { FA Yield } \\
\text { (g-fa/g- } \\
\text { glu) }\end{array}$ & $\begin{array}{c}\text { Total acids } \\
\text { yield } \\
\text { (g-fa/g-glu) }\end{array}$ & $\begin{array}{c}\text { FA } \\
\text { Productivity } \\
\text { (g/l/h) }\end{array}$ & $\begin{array}{c}\text { Eq. base } \\
\text { per eq FA }\end{array}$ \\
\hline $\begin{array}{l}12 \mathrm{~N} \\
\text { Commercial } \\
\mathrm{Mg}(\mathrm{OH})_{2}\end{array}$ & 67 & 0.49 & 0.74 & 1.3 & 1.52 \\
\hline $\begin{array}{l}6 \mathrm{~N} \\
\text { Recycled } \\
\mathrm{Mg}(\mathrm{OH})_{2}\end{array}$ & 48.6 & 0.43 & 0.65 & 0.7 & 1.51 \\
\hline
\end{tabular}

\subsubsection{Conclusions}

The aim of the study was to develop a fermentation process for the production of bio-fumaric acid using Rhizopus oryzae in which $\mathrm{CaCO}_{3}$ as the base was avoided. The replacement of $\mathrm{CaCO}_{3}$ with an alternative base was attractive as it avoided the production of insoluble product calcium fumarate which resulted in a thixotropic culture broth that becomes viscous, reducing oxygen mass transfer and creating complications in product separation. Previous attempts at replacing $\mathrm{CaCO}_{3}$ with alternative bases were unsuccessful (Zhou et al., 2002Roa Engel et al., 2008). This study demonstrated that $\mathrm{Mg}(\mathrm{OH})_{2}$ supported high fumaric acid productivity and titer compared to $\mathrm{NaOH}$ and $\mathrm{KOH}$. Use of $\mathrm{Mg}(\mathrm{OH})_{2}$ as the base not only permitted more control over the fermentation (due to improved mixing and mass transfer) but also allowed the development of a simple and efficient process for fumaric acid separation and purification. The downstream process utilized the solubility of the $\mathrm{Mg}$ fumarate salt at $\mathrm{pH}>4.0$ to permit the removal of the hyphal biomass and other fermentation solids by filtration and the insolubility of the free fumaric acid at $<\mathrm{pH} 2.2$ to permit the recovery and purification of fumaric acid from the fermentation beer.

The failure of $\mathrm{NaOH}$ and $\mathrm{KOH}$ to replace $\mathrm{CaCO}_{3}$ and the success using $\mathrm{Mg}(\mathrm{OH})_{2}$ as a base suggested a preference for divalent metal salts by the organism to promote fumaric acid accumulation. Whether this was result of inhibitory effects of monovalent metals as previously suggested (Zhou et al., 2002) or promotion of acid production by divalent metals remains to be determined. Previously, use of $\mathrm{CaCO}_{3}$ as a base in fumaric fermentations was proposed to be advantageous because of its ability to form an insoluble salt of fumarate and thereby remove fumarate inhibition of the fermentation (Rhodes et al., 1959). However, this work demonstrated that product inhibition was not a valid argument as the 
accumulation of high concentrations of soluble fumarate did not have a negative impact on fermentation performance.

While the laboratory scale process appeared to have some unique and beneficial characteristics, it was important to demonstrate the ability to scale this integrated process for the production of bio-fumaric acid to a scale more closely resembling commercial scale. Demonstration of a process at pilot scale (5$10 \%$ of the final production volume) is vital for identifying process issues arise with increase in fermentation volume. In scaling the fumaric acid process to a $2000 \mathrm{~L}$ working volume fermentation tank several factors associated with successful scale up were addressed.

In order to successfully carry out the pilot scale fermentation an extended seed train was developed to allow sufficient seed volume build up to supply a $5 \%(\mathrm{v} / \mathrm{v}$ ) inoculum to the $2000 \mathrm{~L} / 2500 \mathrm{~L}$ (starting volume/total volume) stirred tank pilot vessel.

Factors intrinsic to large scale production that may negatively impact fermentation performance, such as increased hydrostatic pressure at the base of the tank and increased mixing time (as a result of slower agitation rates), are difficult to simulate at small scale. Further, lower mass transfer rates in larger fermenters can result in a lower $\mathrm{DO}_{2}$ levels in larger tanks even at equivalent agitator tip speeds.

Cultivation parameters, gas flow and agitation speed were adapted to be compatible with the larger pilot scale vessel, agitation rates were based on tip speed to ensure that the shear forces in the pilot scale tanks (inoculum and production) were similar to those in the small scale process development fermentors. Scaling with respect to agitator tip speed was employed as fungal fermentation performance has been shown to be impacted by changes in production tank shear forces (Chen et al., 2007; Pollard, et al., 2007).

Successful scale-up of the fumaric acid fermentation to a $3700 \mathrm{~L}$ vessel with $2500 \mathrm{~L}$ final volume demonstrated that the process was not sensitive to the identified scale dependent variables. Impeller tip speed was shown to be suitable parameter for scaling the fumaric acid fermentation.

Furthermore, the simple and efficient downstream recovery/purification process developed at laboratory scale was demonstrated to be equally effective (after some minor modifications were made) when carried out at pilot scale using a RDVF for both biomass removal and product recovery. The RVDF was selected as this is a unit operation that is scalable to commercial production. The scaled up process generated $>130 \mathrm{~kg}$ of white crystalline fumaric acid, with a chemical purity $>95 \%$ that is available for product testing and further analysis.

The purification of fumaric acid through the diester derivative was also demonstrated as a viable method for fumaric recovery.

The conversion of the inorganic $\mathrm{MgSO}_{4}$ salt to higher value $\left(\mathrm{NH}_{4}\right)_{2} \mathrm{SO}_{4}$ was demonstrated both with clean starting material and with fermentation broth, with the reformation of $\mathrm{Mg}(\mathrm{OH})_{2}$. It was possible to reform and recover $\mathrm{Mg}(\mathrm{OH})_{2}$ in a form that gave a stable suspension in water making it suitable to reuse in a fermentation. The reuse of magnesium hydroxide in fermentation was demonstrated.

\section{Economics}

An economic model for the production of fumaric acid by R.oryzae was constructed. Ranges were established for titer and yields that need to be achieved to be compatible with current market prices for fumaric acid. The manufacturing cost (MC) for fumaric acid production is sensitive to the cost of 
dextrose, and an increase of $10 \%$ in yield would reduce manufacturing cost by $5 \mathrm{c} / \mathrm{lb}$, assuming the price of dextrose at $26 \mathrm{c} / \mathrm{lb}$. The purchase price of major equipment was estimated by an Engineering firm. The In Side Battery Limits (ISBL) factor of four and the Chemical Engineering Plant Cost Index (CEPCI) April '08 were used in calculations of capital cost. Ten year straight line depreciation with $5 \%$ maintenance and $1.5 \%$ of property insurance and taxes were included in calculating the fixed cost. Using these assumptions it was projected that the fumaric acid process could be within reach of the current sales price for this fumaric, given our current medium, productivity and the recovery yields we achieved at lab scale.

\subsection{Task C Production of fumaric acid from alternative carbon sources}

\subsubsection{Introduction}

The US Department of Energy Office outlined in the Biomass Multi-year program plan the need for the development of processes for the production of chemicals and materials from biomass. Dicarboxylic acids were identified as chemicals that can be produced by fermentation using renewable resources and have the potential to replace a significant portion of the current petroleum market (Werpy and Petersen, 2004). These acids can be used directly as polymerization monomers or undergo chemical alterations. $\mathrm{MBI}$ developed a fermentation process for the production of fumaric acid, a four-carbon dicarboxylic acid that can be used directly to replace maleic anhydride in the formulation of unsaturated polyester resins. Maleic anhydride had a global consumption of 1,500 k MT worldwide in 2006, more than $50 \%$ of which was used in the production of unsaturated polyester resins.

The process development for the production of fumaric acid used a filamentous fungus, $R$. oryzae, and glucose as carbon source to identify important parameters affecting fermentation performance. Establishing a process that can use biomass derived sugars was a desirable outcome.

\subsubsection{Materials and Methods}

Saccharification. Starch was saccharified via liquefaction and saccharification using commercial enzymes. Starch liquefaction was carried out at $90^{\circ} \mathrm{C}, \mathrm{pH} 5.4$ for $3 \mathrm{~h}$ using Genencor's Spezyme ( $\alpha-$ amylase). Saccharification was carried out at $63^{\circ} \mathrm{C}, \mathrm{pH} 4.2$ for $20 \mathrm{~h}$ using Genencor's Gzyme enzyme cocktail (amyloglucosidase and pullulanase). The saccharified starch had a final concentration of $120 \mathrm{~g} / \mathrm{L}$ glucose.

Microorganism cultivation, Spore plates. Seed cultures were prepared as described above for glucosebased fermentations.

Production medium for shake flask experiments: A 2x stock without sugar was made consisting of: 2.22 $\mathrm{g} \mathrm{KH}_{2} \mathrm{PO}_{4}, 20 \mathrm{~mL} \mathrm{MgSO}$ (100x stock), $20 \mathrm{~mL} \mathrm{ZnSO} 47 \mathrm{H} 2 \mathrm{O}$ [100x] $20 \mathrm{ml} \mathrm{FeCl} 3$ [100x]; water to $915 \mathrm{~mL}$. These components were autoclaved and then $5 \mathrm{~mL}$ of a $[50 \% \mathrm{w} / \mathrm{v}]\left(\mathrm{NH}_{4}\right)_{2} \mathrm{SO}_{4}$ solution and $20 \mathrm{~mL}$ of [100x] tartaric acid were added. For the glucose production medium, $14.5 \mathrm{~mL}$ of [69\%] glucose and 35.5 $\mathrm{mL} \mathrm{H}_{2} \mathrm{O}$ were added to $50 \mathrm{~mL}[2 \mathrm{x}]$ medium, leading to a starting glucose concentration of $\sim 90 \mathrm{~g} / \mathrm{L}$; for xylose production medium, $8.1 \mathrm{~mL}\left[50 \% \mathrm{w} / \mathrm{v}\right.$ ] xylose, $41.9 \mathrm{~mL} \mathrm{H}_{2} \mathrm{O}$ were added to $50 \mathrm{~mL}$ of [2x] production medium, starting xylose concentration of $\sim 40 \mathrm{~g} / \mathrm{L}$. Fermentations were carried out in $250 \mathrm{~mL}$ pleated or baffled flasks at $32^{\circ} \mathrm{C}$ in a gyrotory shaker at $250-300 \mathrm{rpm}$. $\mathrm{pH}$ was controlled manually through the addition of $\mathrm{MgCO}_{3}[17.24 \% \mathrm{w} / \mathrm{v}]$. 


\subsubsection{Results}

Polymeric sugar utilization (starch): Two fumaric acid producing strains were tested for their ability to utilize polymeric sugars. Minor amounts of monomeric sugar were needed to initiate growth, but once started both isolates were able to grow on starch. The performance of NREL 1526, the same strain used under Task B, was tested in a fermentor. The fermentor was inoculated directly from a shake flask, and did not use a seed train. The fermentation started slowly, presumably because sugar hydrolysis was limiting, but the fermentation reached a titer of $58 \mathrm{~g} / \mathrm{L}$ fumaric acid, demonstrating that less expensive sugar streams can be used. Although the titer is lower than seen in glucose fermentations, it should be noted that the fermentation was not optimized and that a less than optimal inoculum was used.

The ability of NRRL 1526 to grow on saccharified starch was also assessed (Table 18). The fumaric acid productivities and yield were improved using processed starch; the titer achieved was lower due to lower initial sugar concentration.

Table 18: Process performance of a fermentation carried out using Rhizopus oryzae 1526 and saccharified starch as carbon source. DO set point was $100 \%$ (controlled by agitation within $800-900$ rpm). Air flow was $0.88 \mathrm{vvm}$, and $\mathrm{CO}_{2}$ flow was $0.044 \mathrm{vvm}$.

\begin{tabular}{|c|c|c|c|c|}
\hline Carbon source & $\begin{array}{c}\text { FA } \\
\text { Titer } \\
\text { (g/L) }\end{array}$ & $\begin{array}{c}\text { FA Yield } \\
\text { (g-fa/g- } \\
\text { glu) }\end{array}$ & $\begin{array}{c}\text { FA } \\
\text { Productivity } \\
\text { (g/l/h) }\end{array}$ & $\begin{array}{c}\text { Eq. base per } \\
\text { eq FA }\end{array}$ \\
\hline $\begin{array}{c}\text { Saccharified } \\
\text { starch }\end{array}$ & 53.5 & 0.46 & 1.57 & 1.71 \\
\hline
\end{tabular}

Use of sucrose as carbon source for fumaric acid fermentation. Sucrose was tested as an alternative sugar substrate for fumarate production. Sucrose could be obtained from sugarcane (Brazil) at a lower cost $(\$ 0.09 / \mathrm{lb})$ than the current starch derived glucose $(\$ 0.15 / \mathrm{lb})$. This would reduce the cost of fumaric acid production by $\$ 0.11 / \mathrm{lb}$. Rhizopus oryzae strains 1526 and 2582 were tested in shake flasks for the use of sucrose as carbon source. Rhizopus oryzae 1526 did not consume sucrose, whereas Rhizopus oryzae 2582 utilized sucrose for growth and acid production. Two varieties of sucrose were tested, one was sucrose obtained from a grocery store and the other was bulk sucrose obtained from Brazil. Glucose was used as standard carbon source in the control flask. The initial concentration of sugars in flasks was $40 \mathrm{~g} / \mathrm{L}$. Flasks were inoculated as described previously, and an additional $20 \mathrm{~g} / \mathrm{L}$ sugar was added at $24 \mathrm{~h}$. Flasks containing glucose had the highest fumaric titer $(11.6 \mathrm{~g} / \mathrm{L})$ after $48 \mathrm{~h}$, whereas sucrose containing flasks had lower fumarate titers (Figure 5). The overall performance indicated that Rhizopus oryzae 2582 was a suitable organism for fumaric acid production using sucrose as carbon source. 


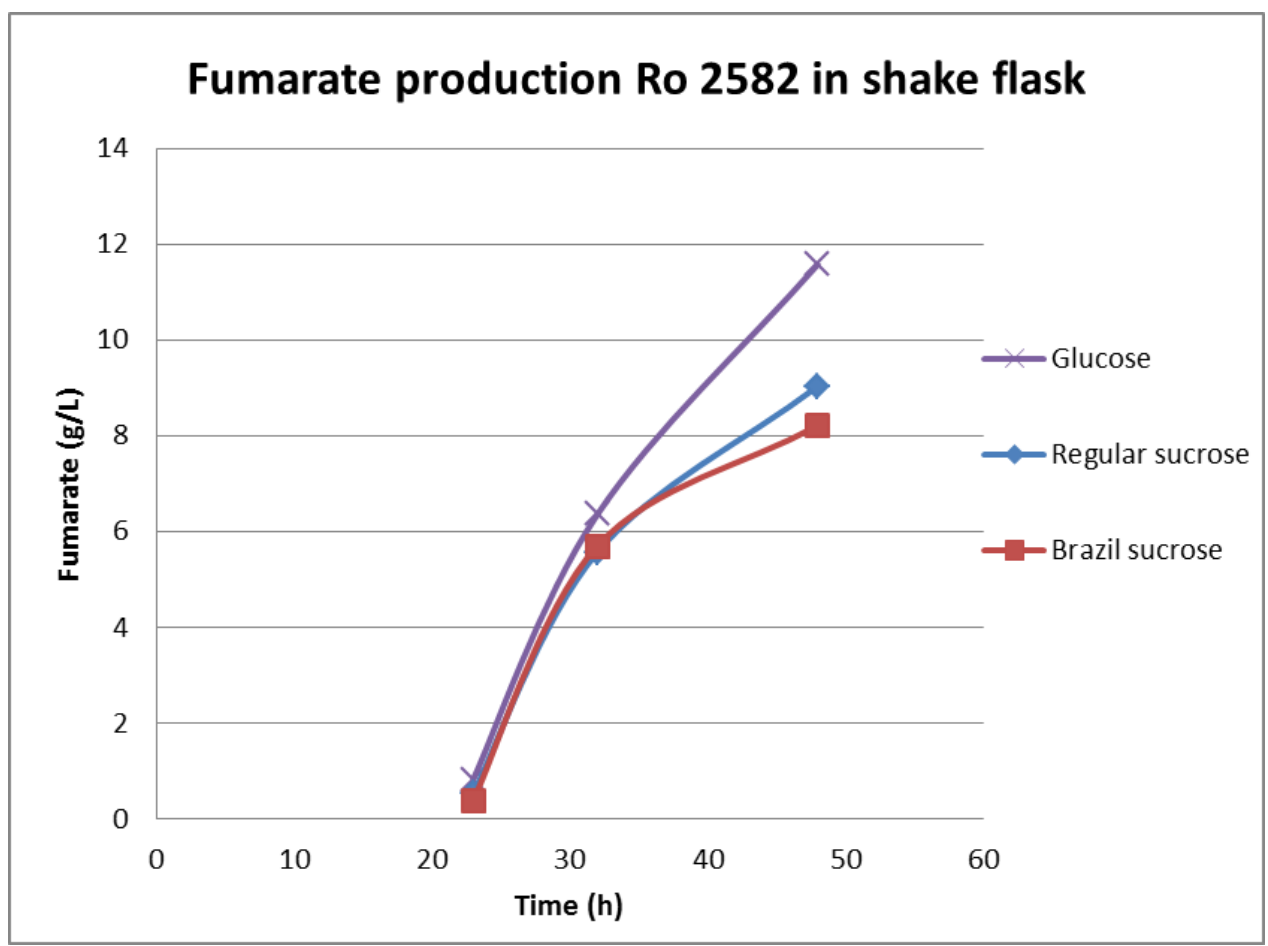

Figure 5: Fumarate production by utilization of glucose and sucrose as carbon source by $R$. oryzae 2582 in shake flasks. Starting sugar concentration: $40 \mathrm{~g} / \mathrm{L}$, additional $20 \mathrm{~g} / \mathrm{L}$ sugar was added at $24 \mathrm{~h}$.

Rhizopus oryzae 2582 was evaluated in fermentors containing glucose, beet sucrose, or Brazilian cane sucrose (Table 19). The glucose fermentation had a better performance than the sucrose fermentations in terms of productivity and yield. Sucrose fermentation media had a higher viscosity, and sucrose cultures took a long time to develop the usual granular morphology. The higher viscosity and the nonpelleted morphology led to decreased oxygen mass transfer and poorer fermentation performance compared to glucose fermentations. Beet sucrose had a slightly better performance than Brazilian cane sucrose. The process performance of sucrose fermentations may be improved by using a lower starting sucrose concentration and adding a sucrose feed once the growth is complete. A lower starting sucrose medium would have a lower viscosity and facilitate proper morphology development of the organism allowing faster growth of organism due to better oxygen mass transfer. Once the growth is complete, the additional sucrose can be added as a continuous feed based on the sucrose consumption rate. 
Table 19: Process performance of fermentations carried out using Rhizopus oryzae 2582 with different carbon sources: glucose, regular sucrose, and Brazilian sucrose and a recycled $\mathrm{Mg}(\mathrm{OH})_{2}$ base. DO set point was $100 \%$ (controlled by agitation within $800-900 \mathrm{rpm}$ ). Air flow was $0.88 \mathrm{vvm}$, and $\mathrm{CO}_{2}$ flow was $\underline{0.044 \mathrm{vvm} .}$

\begin{tabular}{|c|c|c|c|c|}
\hline Carbon source & $\begin{array}{c}\text { FA Titer } \\
\text { (g/L) }\end{array}$ & $\begin{array}{c}\text { FA Yield } \\
\text { (g-fa/g- } \\
\text { glu })\end{array}$ & $\begin{array}{c}\text { FA } \\
\text { Productivity } \\
\text { (g/L.h) }\end{array}$ & $\begin{array}{c}\text { Eq. base per } \\
\text { eq FA }\end{array}$ \\
\hline Glucose & 80 & 0.54 & 1.99 & 1.33 \\
\hline Beet sucrose & 66 & 0.50 & 1.19 & 1.67 \\
\hline Brazilian sucrose & 59 & 0.44 & 1.07 & 1.77 \\
\hline Brazilian sucrose & 56 & 0.44 & 1.02 & 1.83 \\
\hline
\end{tabular}

Xylose utilization: Literature indicated that $R$. oryzae consumed a variety of sugars. That the isolate routinely used in the fumaric acid fermentation utilized 5-carbon sugars and the consumption rates for C6 and C5 sugars under our fermentation conditions was tested in shake flasks. Maas et al., 2008 reported that a $\mathrm{C} / \mathrm{N}$ ration of $61 / 1 \mathrm{~g} / \mathrm{g}$ ) for xylose, and higher rations for glucose, e.g. $151 / 1 \mathrm{lg} / \mathrm{g}$ ] were optimal for $R$. oryzae. $\mathrm{MBI}$ experiments under Task $\mathrm{B}$ had demonstrated that the phosphorus/nitrogen ratio $(\mathrm{P} / \mathrm{N})$ was important, and led to the medium described above. Initially [2x] production medium contained $62.4 \mathrm{~g} \mathrm{MgCO}_{3} / \mathrm{L}$, and no growth in the production flasks was seen. It was thought that the $\mathrm{pH}$ transition from pH 3.0 (at the end of germination phase) to pH $\sim 9.0$ (in the production medium) was too great for the organism. $\mathrm{MgCO}_{3}$ addition was omitted in subsequent experiments, and $\mathrm{MgCO}_{3}$ was added as a $17 \%(\mathrm{w} / \mathrm{v})$ slurry as needed to maintain the $\mathrm{pH}$. Fermentations were followed over $30 \mathrm{~h}$, and a 'final' point was taken at $102 \mathrm{~h}$, but projected to $48 \mathrm{~h}$ in the graphs (Figure 6). Glucose flasks produced $\sim 24$ $\mathrm{g} / \mathrm{L}$ fumaric, xylose flasks only $\sim 11 \mathrm{~g} / \mathrm{L}$. Consumption rates for glucose were $2.22 \mathrm{~g} / \mathrm{L}-\mathrm{h}(4.5-48 \mathrm{~h}$ EFT) and $0.93 \mathrm{~g} / \mathrm{L}-\mathrm{h}$ for xylose (EFT 8-48 h). The onset of C5 sugar consumption was delayed compared to glucose. None of the sugars were consumed completely in the shake flasks, possibly due to the lack of $\mathrm{pH}$ control. 


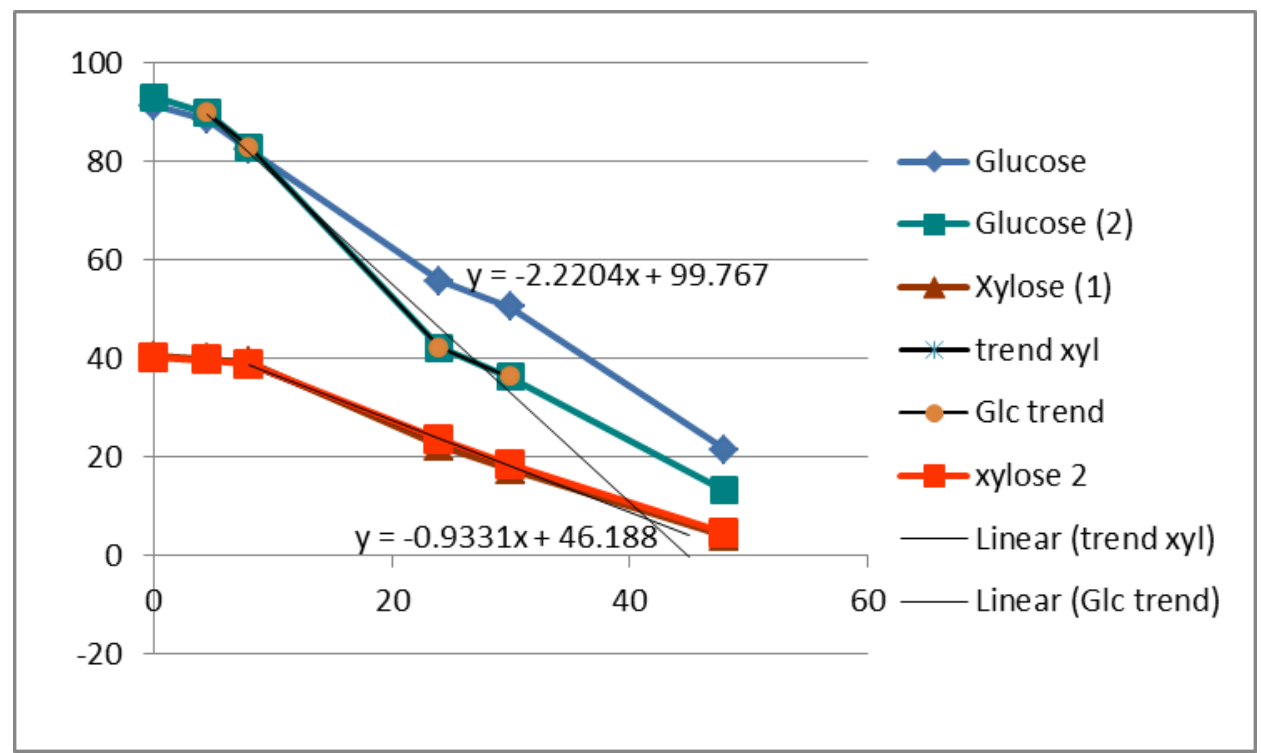

Figure 6: Glucose and xylose consumption in shake flasks.

The experiment was repeated in a stirred tank reactor (Table 20) to determine if C5 consumption rates improved in a more controlled environment. Duplicate fermentations with $\sim 80 \mathrm{~g} / \mathrm{L}$ xylose, performed differently for unknown reasons, with one producing more malic acid co-product. Stirred tank fermentations showed higher consumption rates $(1.4 \mathrm{~g} / \mathrm{L} . \mathrm{h})$ than the shake flasks. Glucose consumption rates in fermentors were $\approx 4.1 \mathrm{~g} / \mathrm{L} . \mathrm{h}$.

Table 11: Fermentation performance in xylose fermentations. Fermentations were controlled in the same manner as standard glucose fermentations. Xylose was the sole carbon source.

\begin{tabular}{|c|c|c|c|c|}
\hline $\begin{array}{l}\text { Fumaric acid } \\
\text { titer } \\
{[\mathrm{g} / \mathrm{l}]}\end{array}$ & $\begin{array}{l}\text { Malic acid titer } \\
{[\mathrm{g} / \mathrm{l}]}\end{array}$ & $\begin{array}{l}\text { Xylose } \\
\text { consumption } \\
\text { rate } \\
\text { [g/l-h] }\end{array}$ & $\begin{array}{l}\text { Yield } \\
\text { [g fumaric/ g } \\
\text { xylose] }\end{array}$ & $\begin{array}{l}\text { Productivity } \\
{[\mathrm{g} / \mathrm{I}-\mathrm{h}]}\end{array}$ \\
\hline 34.6 & 23.5 & 1.4 & 0.5 & 0.65 \\
\hline 18.3 & 43.3 & 1.3 & 0.3 & 0.33 \\
\hline
\end{tabular}

$R$. oryzae had been prepared using a seed train using glucose. Therefore the lag in xylose consumption could have been caused by glucose repression. The fermentation was repeated using a xylose-based seed train. As a control the standard, glucose medium was also used. Xylose germinated spores were transferred to xylose production medium (Flasks 5, 6, Figure 7) and mixed sugar production medium (Flasks 7,8 ), glucose germinated spores were transferred to glucose production medium (Flasks 1, 2), as a control, and mixed sugar medium (Flasks 3, 4, Figure 10). Mixed sugar concentrations were tested at starting concentrations of $\sim 80 \mathrm{~g} / \mathrm{L}$ glucose plus $40 \mathrm{~g} / \mathrm{L}$ xylose (Flasks 3,7 , Figure 7), and $40 \mathrm{~g} / \mathrm{L} \mathrm{glucose}$ plus $40 \mathrm{~g} / \mathrm{L}$ xylose (Flasks 4, 8), to assess, if higher glucose concentrations led to faster carbon consumption rates. 

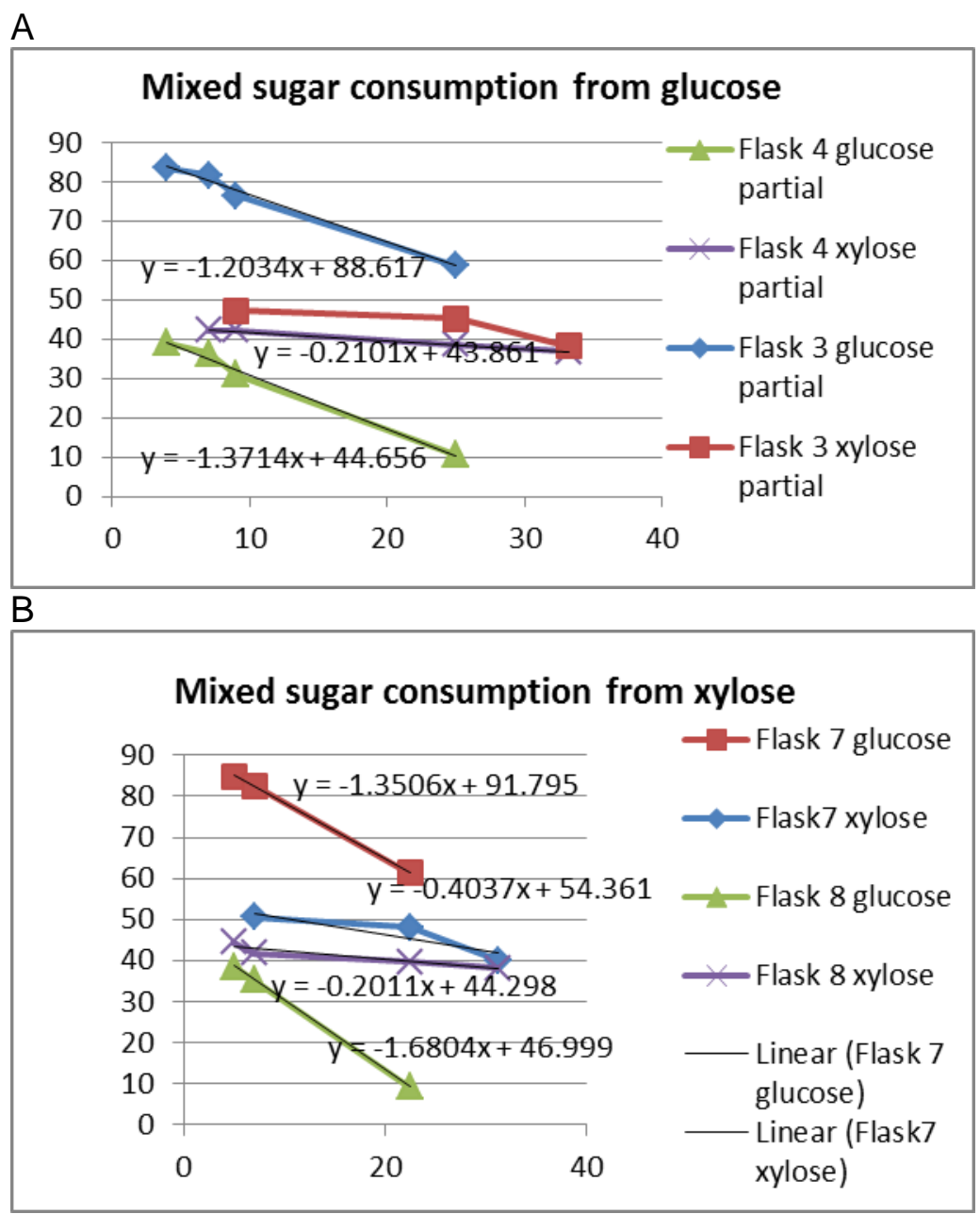

Figure 7: Sugar consumption of glucose and xylose by R. oryzae. NRL 1526 was transferred from either glucose $(A)$ or xylose (B) germination medium to mixed sugar containing production medium.

The sugar consumption rates for both sugars were slower than previously observed. The presence of xylose in the germination medium did improve consumption of xylose. In all cases glucose was consumed almost immediately after transfer into the production flasks, and xylose consumption began after a lag period. In mixed sugar cultures xylose consumption started before glucose was completely consumed. Starting sugar concentrations had no effect on consumption rates. Although the $R$. oryzae appeared to favor the consumption of glucose, it can sporulate and germinate in the absence of glucose. Germination on xylose exhibited different characteristics in terms of duration (time) and $\mathrm{pH}$. Fermentative production of an organic acid in shake flasks was complicated by the lack of $\mathrm{pH}$ control. Although results clearly state the $R$. oryzae had preference for glucose over xylose, the precise consumption rates for each sugar may have been affected by the variable $\mathrm{pH}$ control. 
Fermentations with biomass derived sugars.

AFEX treated corn stover was subjected to enzyme hydrolysis. The sugar stream generated was analyzed using standard procedures (Table 22).

Table 22: Sugar analysis of enzyme hydrolysed, AFEX-treated corn stover. Solids loading was $25 \% \mathrm{w} / \mathrm{v}$ and hydrolysis was carried out following procedure NREL-LAP-009.

\begin{tabular}{|c|c|c|c|c|c|}
\hline $\begin{array}{c}\text { Cellobiose } \\
{[\mathrm{g} / \mathrm{L}]}\end{array}$ & $\begin{array}{c}\text { Glucose } \\
{[\mathrm{g} / \mathrm{L}]}\end{array}$ & $\begin{array}{c}\text { Xylose } \\
{[\mathrm{g} / \mathrm{L}]}\end{array}$ & $\begin{array}{c}\text { Galactose } \\
{[\mathrm{g} / \mathrm{L}]}\end{array}$ & $\begin{array}{c}\text { Arabinose } \\
{[\mathrm{g} / \mathrm{L}]}\end{array}$ & $\begin{array}{c}\text { Mannose } \\
{[\mathrm{g} / \mathrm{L}]}\end{array}$ \\
\hline 3.12 & 54.59 & 24.81 & 1.26 & 4.75 & 0.27 \\
\hline
\end{tabular}

The AFEX-derived sugar stream was diluted $x 2$ in shake flask experiments and was supplemented with standard medium components. A sugar stream of similar composition was prepared from "clean" sugars as a control. The $\mathrm{pH}$ of the flask fermentation was controlled through base addition at multiple time points, permitting $\mathrm{pH}$ control between $\mathrm{pH}$ 5-8. Clean sugar flasks utilized the glucose and xylose as previously observed. Consumption of the minor sugar components was negligible. Hydrolysate glucose and xylose were readily consumed, at a faster rate and more completely than clean sugar controls (Figure 8). Cellobiose was also consumed in the hydrolyates, but arabinose and mannose were not. These results demonstrated that the hydrolysate sugar can be metabolized by the $R$. oryzae and no growth inhibition was seen (Figure 8 ). The product profiles differed significantly between the clean sugar and the hydrolysate flasks. Fumaric acid production did not occur in hydrolysate containing flasks, and high amounts of biomass were produced. Nitrogen analysis demonstrated that hydrolysates contained high concentrations of nitrogen, carried over presumably from the AFEX treatment. Fumaric acid production is triggered by $\mathrm{N}$-starvation and the hydrolysate containing flasks never achieved $\mathrm{N}$ depletion. Although AFEX-derived sugar streams supported good growth of $R$. oryzae (no inhibitory compounds were present) their use with the current process seems problematic. An altered fermentation process would be required that can induce acid production phase through the limitation of a factor other than nitrogen. 


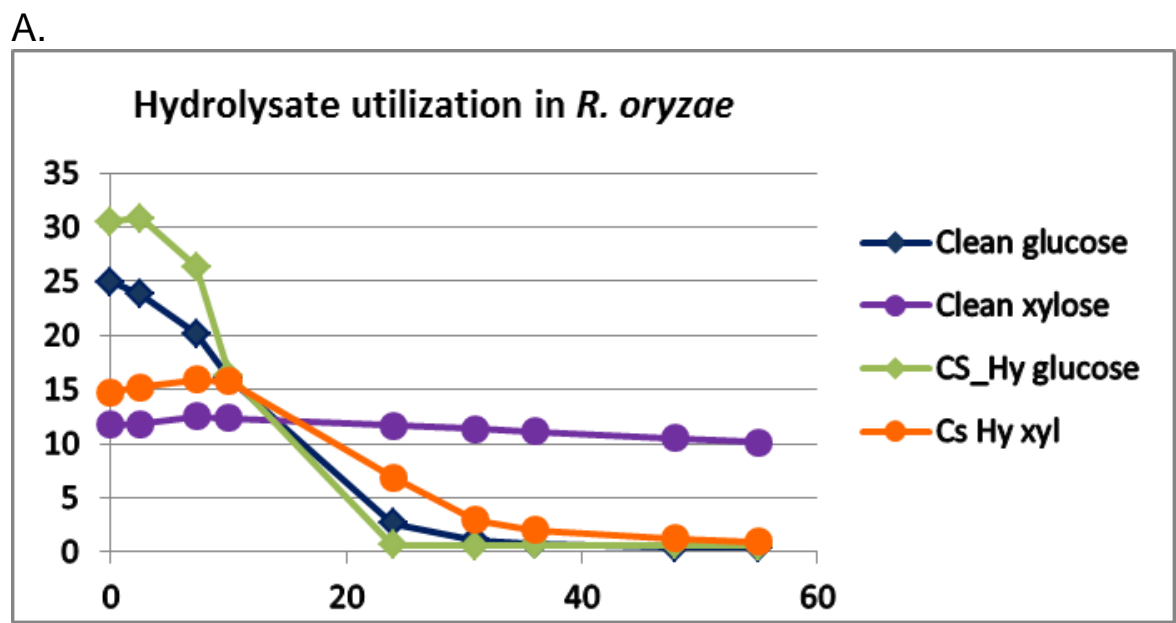

B:

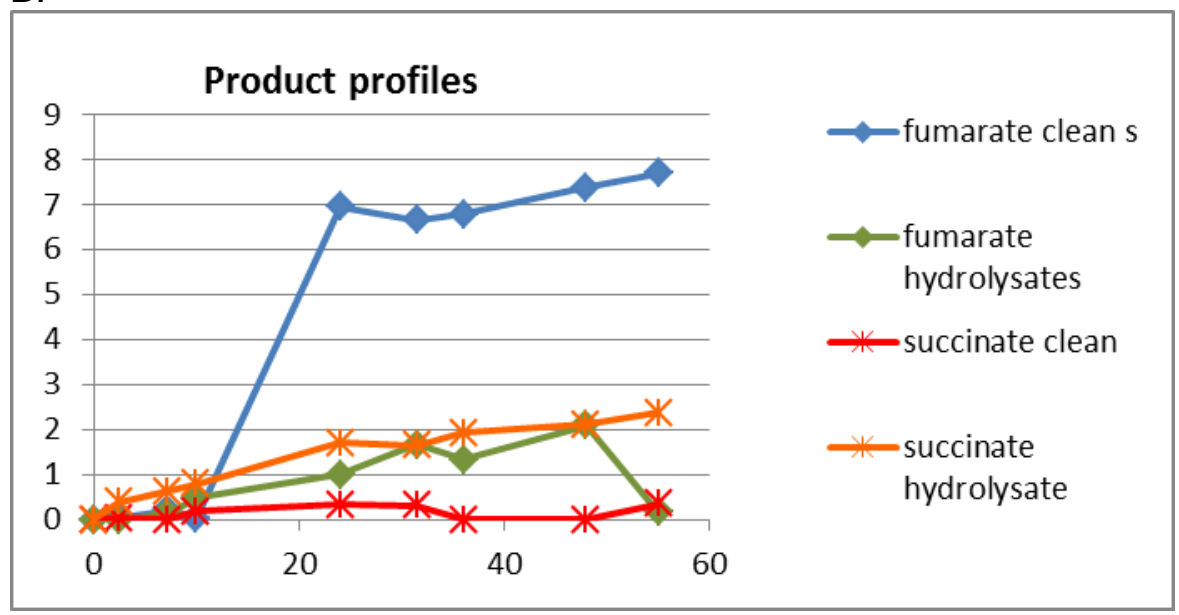

Figure 8: Use of corn stover hydrolysates as carbon source in fumaric fermentations. (A). Sugar consumption(B). Acid accumulation.

AFEX pretreated and enzyme hydrolyzed corn stover was used as carbon source for a STR fermentation. The composition of sugars in biomass hydrolysate was glucose $69 \mathrm{~g} / \mathrm{L}$, xylose $36 \mathrm{~g} / \mathrm{L}$, galactose $2 \mathrm{~g} / \mathrm{L}$, and arabinose $7.4 \mathrm{~g} / \mathrm{L}$ (Table 22). Since $\mathrm{NH}_{3}$ was used in the AFEX pretreatment of biomass, the hydrolyate contained significant nitrogen. The hydrolysate was diluted $2.7 \mathrm{x}$ to obtain the required nitrogen concentration used in the fumaric acid fermenation. Reagent grade glucose and xylose were added to make up the original sugar concentrations in the hydrolysate. $R$. oryzae consumed glucose before utilizing xylose in fermentor (Figure 9), which is consistent with the observations in shake flask studies. After glucose was fully consumed, fumarate titer was $20 \mathrm{~g} / \mathrm{L}$. Thereafter, fumarate concentration decreased while the malic acid concentration increased. It was hypothesized that malic acid was produced by xylose utilization as well as by conversion of fumarate to malate. Xylose and malic acid coelute on the HPLC protocol used and therefore, xylose concentrations were determined separately to arrive at approximate concentration of malic acid. These results are consistent with observations using pure xylose. Other sugars, galactose and arabinose, were not utilized. It was demonstrated that $R$. 
oryzae can utilize, glucose and xylose, from biomass hydrolysate derived sugar stream for growth and fumaric acid production, albeit less effectively than on glucose alone.

Table 22: Sugar analysis of enzyme hydrolysed, AFEX-treated corn stover. Solids loading was $20 \%$.

\begin{tabular}{|l|l|l|l|}
\hline $\begin{array}{l}\text { Glucose } \\
{[\mathrm{g} / \mathrm{l}]}\end{array}$ & $\begin{array}{l}\text { Xylose } \\
{[\mathrm{g} / \mathrm{l}]}\end{array}$ & $\begin{array}{l}\text { Galactose } \\
{[\mathrm{g} / \mathrm{l}]}\end{array}$ & $\begin{array}{l}\text { Arabinose } \\
{[\mathrm{g} / \mathrm{l}]}\end{array}$ \\
\hline 68.85 & 35.86 & 2.15 & 7.43 \\
\hline
\end{tabular}

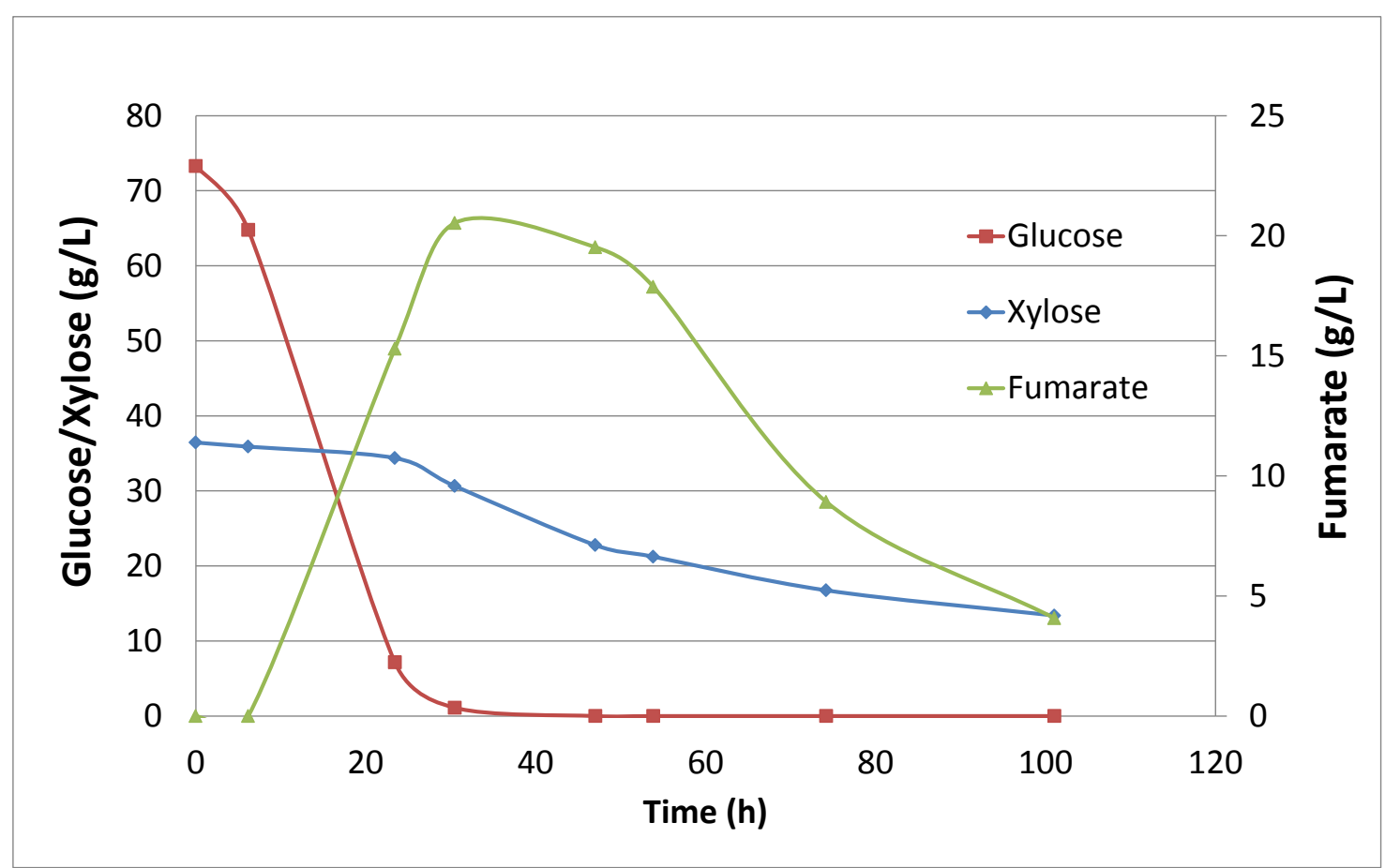

Figure 9: Corn stover hydrolysates as carbon source in fumaric fermentations

\subsubsection{Conclusions}

$R$. oryzae can utilize a variety of carbon substrates. Sucrose and starch are less expensive carbon sources and can be fermented to form fumaric acid, although optimization is necessary to achieve comparable performance to glucose fermentations.

Consumption rates for xylose were slower than those for glucose in the isolates tested, and when both sugars were present, glucose was be utilized preferentially. Xylose consumption began before the glucose was completely consumed, indicating that $R$. oryzae does not have strict glucose repression mechanisms as has been described for yeast. Other biomass derived sugars were not utilized in the isolates we tested. Other Rhizopus species have been reported to be able to utilize arabinose and other 6-carbon sugars (McMillan \& Boynton, 1994).

The onset of acid production upon $\mathrm{N}$-limitation is a feature of filamentous fungi. As expected, this was confirmed to be the case for fumaric production by $R$. oryzae. AFEX-treatment of biomass to generate sugar streams at the concentrations used was not compatible with fumaric acid production by this organism. 


\subsection{References}

1. Chaney A.L., and Marbach E.P. 1962. Modified reagents for determination of urea and ammonia. Clin Chem 8:130-132.

2. Chen Y., Jiang W., Liang D.T., Tay J.H. 2007. Structure and stability of aerobic granules cultivated under different shear force in sequencing batch reactors. Appl. Microbiol. Biotechnol. 76:1199-208.

3. Gangl, I.C., Weigand W.A., Keller F.A. 1990. Economic comparison of calcium fumarate and sodium fumarate production by Rhizopus arrhizus. Appl. Biochem. Biotechnol. 24-25:663-677.

4. Kenealy W., Zaady E., Dupreez J.C., Stieglitz B., Goldberg I. 1986. Biochemical aspects of fumaric acid accumulation by Rhizopus arrhizus. Appl. Environ. Microbiol. 52:128-133.

5. Ling L.B., Ng T.K. 1989. Fermentation process for carboxylic acids. US Patent 4877731.

6. Ng T., Hesser R.J., Stieglitz B., Griffiths B.S., Ling L.B. 1986. Production of tetrahydrofuran/1,4 butanediol by a combined biological and chemical process. Biotech. Bioeng. Symp. 17:344-363.

7. Osmani S.A., and Scrutton M.C. 1985. The sub-cellular localisation and regulatory properties of pyruvate carboxylase from Rhizopus arrhizus. Eur. J. Biochem. 147:119-28.

8. Overman S.A., and Romano A.H. 1969. Pyruvate carboxylase of Rhizopus nigricans and its role in fumaric acid production. Biochem. Biophys. Res. Commun. 37:457-63.

9. Pollard D.J., Kirschner T.F., Hunt G.R., Tong I.T., Stieber R., Salmon P.M. 2007. Scale up of a viscous fungal fermentation: application of scale-up criteria with regime analysis and operating boundary conditions. Biotechnol. Bioeng. 96:307-17.

10. Rhodes R.A., Moyer A.J., Smith M.L., Kelley S.E. 1959. Production of fumaric acid by Rhizopus arrhizus. Appl. Microbiol. 7:74-80.

11. Rhodes R.A., Lagoda A.A., Misenheimer T.J., Smith M.L., Anderson R.F., and Jackson R.W. 1962. Production of Fumaric Acid in 20-Liter Fermentors. Appl. Microbiol. 10:9-15.

12. Roa Engel C.A., Straathof A.J., Zijlmans T.W., van Gulik W.M., and van der Wielen L.A. 2008. Fumaric acid production by fermentation. Appl. Microbiol. Biotechnol. 78:379-89.

13. Werpy T., and Petersen G. 2004. Top Ten Value Added Chemicals from Biomass. Volume I. U.S. Department of Energy, USA.

14. Zhou Y., Du J., and Tsao G.T. 2002, Comparison of Fumaric Acid Production by Rhizopus oryzae using different neutralizing agents. Bioprocess. Biosyst. Eng. 25, 179-181. 
15. Maas, R.H.W., Springer, J., Eggink, G., Weusthuis, R.A., 2008, J. Ind. Microbiol. Biotechnol. 35, 569578 , Xylose metabolism in the fungus Rhizopus oryzae: effect of growth and respiration on $L(+)$ lactic acid production.

16. McMillan, J.D. and Boynton, B. 1994, Appl. Biochemistry and Biotechnology 45-46, 569-584; Arabinose utilization by xylose fermenting yeasts and fungi.

17. (Erwin and Gottschilch, 1993).

18. Flatland-Bloom et al. 2009, US Patent Application US2009/0042264 A1; Rhizopus pyruvatecarboxylase overexpression.

19. Bonner, O. D., Smith, L.L. 1957, J. Phys. Chem. 61, 326-329.

20. Desai, Ruchir P. and Eleftherios T. Papoutsakis, 1999, Appl. \& Environ. Microbiol. 65 (3), 936-945.

21. Guettler, M.V., Jain, M.K., Rumler, D. 1996, U.S. Patent 5,573,931.

22. Guettler, M.V., Jain, M.K., Soni, B.K. 1998, U.S.Patent 5,723,322 .

23. Guettler, M.V., Rumler, D., Jain, M.K. 1999, Internat. Journ. Systematic Bacteriology 49, 207-216.

24. McKinley, J.B., Zeikus, J.G., Vieille, C. 2005, Appl. Environmental Microbiol. 71, 6651-6656.

25. Schweitzer, P. A. Handbook of Separation Techniques for Chemical Engineers, $3^{\text {rd }}$ Edition, McGrawHill: New York, NY, 1997.

26. Van der Werf, M. J., Guettler, M. V., Jain, M. K., and Zeikus, J. G. 1997, Arch. Microbiol. 167: 332342.

27. Yi, J., Guettler, M.V., Kleff, S. 2005, US Patent Application

28. Kim, P., Laivenieks, M., McKinley, J., Viieille, C., Zeikus, G.J. 2004, Plasmid, 222-222.

29. Battersby, A.R., Cardwell, K.S., Leeper, F. J. 1986, J. Chem. Soc. Perkin Trans. 1, 1565-1580.

30. Bonner, O. D., Smith, L.L. 1957, J. Phys. Chem. 61, 326-329.

31. Desai, Ruchir P. and Eleftherios T. Papoutsakis, 1999, Appl. \& Environ. Microbiol. 65 (3), 936-945.

32. Erwin, Alice L. and Emil C. Gottschilch. 1993, J. Biol. Chem. 248, 7012-7017, Purification and properties of membrane - bound D-Lactate dehydrogenase from E. coli.

33. Guettler, M.V., Jain, M.K., Rumler, D. 1996, U.S. Patent 5,573,931.

34. Guettler, M.V., Jain, M.K., Soni, B.K. 1998, U.S.Patent 5,723,322 .

DE-FG36-07G087005

Final Report - 11/29/2011

$\mathrm{MBI}$ International

Page $\mathbf{4 5}$ of $\mathbf{4 9}$ 
35. Guettler, M.V., Rumler, D., Jain, M.K. 1999, Internat. Journ. Systematic Bacteriology 49, 207-216.

36. Hügler, M., Wirsen, C.O., Fuchs, G., Taylor, C.D., Sievert, S.M. 2005, Journal of Bacteriol. 187, 30203027.

37. McKinley, J.B., Zeikus, J.G., Vieille, C. 2005, Appl. Environmental Microbiol. 71, 6651-6656.

38. L.B. Ling and T.K Ng, 1989, U.S. Patent 4,877,731, Fermentation process for carboxylic acids.

39. Paolini, V. 1902, Gazzetta Chimica Italiana 21, 403-409.

40. Peng, L. and K. Shimizu, 2003, Appl. Microbiol. Biotech. 61, 163-178.

41. Sambrook, J., Fritsch, E. F. and Maniatis, T. Molecular Cloning: A Laboratory Manual; Cold Spring Harbor Laboratory: Plainview, NY, 1990.

42. Schweitzer, P. A. Handbook of Separation Techniques for Chemical Engineers, $3^{\text {rd }}$ Edition, McGrawHill: New York, NY, 1997.

43. Yi, J., Guettler, M.V., Kleff, S. 2005, US Patent Application

\subsection{Products Developed}

Kleff, S., Presentation to Bayer-Material Sciences, Leverkusen, Germany, February 2008.

Kleff, S., Presentation to DSM, Delft, Netherlands, February 2008.

Kleff, S., Presentation to BASF Ludwigshafen, Germany, February 2008.

Michael V. Guettler*, Denise S. Rumler*, Sachin Jadhav*, James Wynn*, Robert J. Hanchar*, Xuewen Chen", Yair Shachar-Hill", Susanne Kleff*, A Novel Process for the Production of Fumaric Acid, August 02, 2010, SIM Annual Meeting San Francisco, CA.

Robert Hanchar*, Michael Guettler, Susanne Kleff, Denise Rumler, Sachin Jadhav, Jim Wynn, Fatmagul Tuluoglu. "Production and Recovery of Bio-Based Fumaric Acid Using a Novel Process", Poster presentation in the Division of Biochemical Technology at the American Chemical Society $241^{\text {st }}$ Nation Meeting, Spring 2011 March 27 31, 2011, Anaheim, CA

Robert Hanchar*, Fatmagul Tuluoglu, Heather Hodge, Michael Guettler, Sachin Jadhav, and Susanne Kleff. "By-Product Reduction in Fermentative Carboxylic Acid Production Processes", Poster presentation at the $33^{\text {rd }}$ Symposium on Biotechnology for Fuels and Chemicals May 2-5, 2011, Seattle, WA

Michael V. Guettler, Sachin Jadhav, Denise S. Rumler, Benjamin Haller, James Wynn, Claire Vieille", Susanne Kleff: "Process development for the production of organic acids". July 25, 2011, SIM Annual Meeting, New Orleans, LA.

DE-FG36-07G087005

Final Report - 11/29/2011

$\mathrm{MBI}$ International

Page 46 of 49 
Robert Hanchar*, Michael Guettler, Susanne Kleff, Denise Rumler, Sachin Jadhav, Jim Wynn, Fatmagul Tuluoglu. "Production and Recovery of Bio-Based Fumaric Acid Using a Novel Process", Poster presentation in the Division of Biochemical Technology at the American Chemical Society $241^{\text {st }}$ Nation Meeting, Spring 2011 March 27 31, 2011, Anaheim, CA

Robert Hanchar*, Fatmagul Tuluoglu, Heather Hodge, Michael Guettler, Sachin Jadhav, and Susanne Kleff. "By-Product Reduction in Fermentative Carboxylic Acid Production Processes", Poster presentation at the $33^{\text {rd }}$ Symposium on Biotechnology for Fuels and Chemicals May 2-5, 2011, Seattle, WA

Four presentations to interested industrial partners were made on mbi's fumaric acid process.

US Patent Application 12/488,417 (US 2010/0323416 A1), filed June 19, 2009; Guettler, M.V., Hanchar, R.J., Rumler, D.S., Kleff, S. Fermentation Method using a Magnesium Compound Containing Oxygen.

US Patent application US 13/039,913, filed March 03, 2011: Hanchar, R.J., Kleff, S., Guettler, M.V., "Production of carboxylic acids and salt co-products". 